\title{
Extending differential optical absorption spectroscopy for limb measurements in the UV
}

\author{
J. Puķīte ${ }^{1}$, S. Kühl ${ }^{1}$, T. Deutschmann ${ }^{2}$, U. Platt ${ }^{2}$, and T. Wagner ${ }^{1}$ \\ ${ }^{1}$ Max Planck Institute for Chemistry, J. J. Becher Weg 27, 55128 Mainz, Germany \\ ${ }^{2}$ Institute of Environmental Physics, University of Heidelberg, Im Neuenheimer Feld 229, 69120 Heidelberg, Germany
}

Received: 24 September 2009 - Published in Atmos. Meas. Tech. Discuss.: 18 November 2009

Revised: 6 May 2010 - Accepted: 10 May 2010 - Published: 19 May 2010

\begin{abstract}
Methods of UV/VIS absorption spectroscopy to determine the constituents in the Earth's atmosphere from measurements of scattered light are often based on the BeerLambert law, like e.g. Differential Optical Absorption Spectroscopy (DOAS). While the Beer-Lambert law is strictly valid for a single light path only, the relation between the optical depth and the concentration of any absorber can be approximated as linear also for scattered light observations at a single wavelength if the absorption is weak. If the light path distribution is approximated not to vary with wavelength, also linearity between the optical depth and the product of the cross-section and the concentration of an absorber can be assumed. These assumptions are widely made for DOAS applications for scattered light observations.

For medium and strong absorption of scattered light (e.g. along very long light-paths like in limb geometry) the relation between the optical depth and the concentration of an absorber is no longer linear. In addition, for broad wavelength intervals the differences in the travelled light-paths at different wavelengths become important, especially in the $\mathrm{UV}$, where the probability for scattering increases strongly with decreasing wavelength.

However, the DOAS method can be extended to cases with medium to strong absorptions and for broader wavelength intervals by the so called air mass factor modified (or extended) DOAS and the weighting function modified DOAS. These approaches take into account the wavelength dependency of the slant column densities (SCDs), but also require a priori knowledge for the air mass factor or the weighting function from radiative transfer modelling.
\end{abstract}

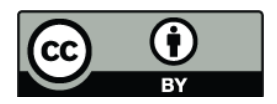

Correspondence to: J. Pukīte

(janis.pukite@mpic.de)
We describe an approach that considers the fitting results obtained from DOAS, the SCDs, as a function of wavelength and vertical optical depth and expands this function into a Taylor series of both quantities. The Taylor coefficients are then applied as additional fitting parameters in the DOAS analysis. Thus the variability of the SCD in the fit window is determined by the retrieval itself.

This new approach provides a description of the SCD the exactness of which depends on the order of the Taylor expansion, and is independent from any assumptions or a priori knowledge of the considered absorbers.

In case studies of simulated and measured spectra in the UV range (332-357 nm), we demonstrate the improvement by this approach for the retrieval of vertical profiles of $\mathrm{BrO}$ from the SCIAMACHY limb observations. The results for $\mathrm{BrO}$ obtained from the simulated spectra are closer to the true profiles, when applying the new method for the SCDs of ozone, than when the standard DOAS approach is used. For the measured spectra the agreement with validation measurements is also improved significantly, especially for cases with strong ozone absorption.

While the focus of this article is on the improvement of the $\mathrm{BrO}$ profile retrieval from the SCIAMACHY limb measurements, the novel approach may be applied to a wide range of DOAS retrievals.

\section{Introduction}

Differential Optical Absorption Spectroscopy (DOAS) (Platt and Stutz, 2008) is nowadays widely used to derive trace gas abundances in the atmosphere, either from direct or scattered light observations (e.g. Perner et al., 1976; Platt and Perner,

Published by Copernicus Publications on behalf of the European Geosciences Union. 
1980; Mount et al., 1987; Solomon et al., 1987; Wahner et al., 1990; Burrows et al., 1999; Platt and Stutz, 2008; Wagner et al., 2008).

For direct light observations, the light path is well defined and the detected integrated number density along the light path, the slant column density (SCD) is related to the vertical column density $(\mathrm{VCD}$, being the number density integrated along the altitude) by an enhancement factor (so called air mass factor, AMF). The AMF only depends on the observation angle and can be calculated by simple trigonometry. For observations of scattered light, which are usually characterized by complex viewing geometries, this enhancement factor is no longer a pure geometric quantity but depends strongly on the individual light paths contributing to the measurement (e.g. Solomon et al., 1987; Perliski and Solomon, 1993). Therefore, the interpretation of the measurements requires advanced radiative transfer modelling (RTM) and inversion algorithms, especially for observations at large solar zenith angle (SZA) or for limb observations (i.e., at tangential view from the satellite into the Earth's atmosphere).

The AMF for scattered light observations depends on all factors that impact light propagation in the atmosphere (like the SZA, the air density, the abundance of absorbers e.g. ozone, as well as clouds, aerosols, albedo etc.). In particular, due to the dependence of the propagation of light on scattering and absorption processes, the AMF is a function of wavelength and the absorption strength (Marquard et al., 2000). For the application of DOAS this means that the relation between SCD and VCD may vary considerably within the wavelength interval chosen for a DOAS fit (Platt et al., 1997).

While the wavelength dependency of the SCD can be neglected for many applications, it was found that it becomes important for cases with strong absorption (e.g., absorption by ozone in the UV) and large SZA for satellite nadir and ground observations (Diebel et al., 1995; Richter, 1997). For limb geometry, where the atmosphere is observed in a tangential view, a correction for these effects is even more necessary due to the increased light path lengths.

A common approach for this correction is the so called AMF modified or extended DOAS (Diebel et al., 1995; Richter, 1997) which considers the product of the AMFs and the absorption cross-sections in the DOAS analysis instead of the cross-sections alone. Thus, wavelength independent VCDs are fitted directly.

Alternatively, the weighting function DOAS method (Buchwitz et al., 2000; Coldewey-Egbers et al., 2004, 2005; Frankenberg et al., 2005) was developed. It accounts for the wavelength modulation of the slant path by approximating the measured optical depth with a Taylor expansion around the reference intensity at a certain a priori state plus a low order polynomial. For limb observations the so called full retrieval approach was developed (Rozanov et al., 2005), modelling the intensities for all altitudes of one particular limb scanning sequence simultaneously.
In this article, we propose a method that takes into account the dependency of SCD on optical depth and on wavelength already in the fitting procedure itself. Thus, wavelength dependent SCDs are determined by DOAS. The pre-calculation of AMFs or weighting functions and intensities is not required, and the approach does not need a priori input for the retrieval of SCDs. The method is based on the formulation of the AMFs (and consequently SCDs) as function of wavelength and optical depth of strong absorbers: a Taylor series expansion for AMFs or SCDs with respect to the wavelength and absorption by trace gases is performed.

The terms of this series are then co-fitted by the least squares approach like the absorption cross-sections in the standard DOAS analysis. From the fitted coefficients, the functional relationship of the SCDs on wavelength and absorption can be determined and taken into account to the precision of the order of the Taylor series expansion.

We study the capability and limitations of the method for the retrieval of vertical $\mathrm{BrO}$ profiles from $\mathrm{EN}-$ VISAT/SCIAMACHY limb measurements in the near UV spectral region $(332-357 \mathrm{~nm})$. The method is applied for simulated spectra for different fit windows to investigate its importance and performance for different spectral regions. Also, to verify that the approach can be applied for improved retrievals from actual measurement data, we compare the obtained $\mathrm{BrO}$ profiles to those from correlated balloon observations performed for the validation of SCIAMCHY limb measurements.

The article is structured as follows: in Sect. 2 we describe the standard DOAS approach, its limitations for strong absorptions and limb geometry, and introduce the Taylor series approach to overcome this problem. Section 3 demonstrates the applicability of the approach to synthetic spectra, and Sect. 4 studies the sensitivity of the novel approach for different absorption strengths, geometries, fit windows and fit parameters. Section 5 shows the application of the approach to real measurements of SCIAMACHY and compares the result with correlated balloon measurements (Dorf et al., 2006). Finally, Sect. 6 draws some conclusions.

\section{The method}

\subsection{Standard DOAS: principle and limitations for strong absorptions and scattered light}

\subsubsection{Standard DOAS}

Differential Optical Absorption Spectroscopy (Platt, 1994) is an atmospheric spectroscopy method based on a modified Beer-Lambert law (extended to observations of scattered light), see e.g. Stutz and Platt (1996); Platt and Stutz (2008). To determine the SCDs $S$ of the considered absorbing trace gases, DOAS utilizes their spectral features: the algorithm simultaneously fits the SCDs $S_{i}$ of a number of $k$ absorbers 
with known absorption cross-sections $\sigma_{i}$ to the difference of the logarithm of a measured spectrum $I$ and a reference spectrum $I_{0}$ :

$\ln \frac{I_{0}(\lambda)}{I(\lambda)}=\sum_{i=1}^{k} \sigma_{i}(\lambda) \cdot S_{i}+\underbrace{\sum_{p=1}^{l} a_{p} \lambda^{p}}_{P}$

Usually, the absorption due to trace gases shows a strong variation with wavelength $\lambda$. It is described by the absorption cross sections of the considered molecules that are known from laboratory measurements. Structures due to scattering, which vary only slowly with wavelength, are described by a broad band polynomial $P$ (last term in Eq. 1) of order $l$ in the fit analysis (Platt, 1994). The reference spectrum does not include the trace gas absorptions or only contains a small amount. For satellite observations usually a direct Sun spectrum, or - for limb geometry - a spectrum measured at high tangent height (TH), where the considered trace gas has low concentration, is applied as reference spectrum. In a least squares fit, the differences between the right and left terms of Eq. (1) are minimized for all wavelengths simultaneously providing as result the SCDs $S_{i}$ and polynomial coefficients $a_{p}$ that fit best to the respective measurement.

The SCD is related to the VCD as the product of AMF $A_{i}$ and VCD $V_{i}$ :

$S_{i}=A_{i} \cdot V_{i}$

Equations (1) and (2) are simplifications in so far as the wavelength dependency of AMF and SCD is not considered. This simplification can be applied for a wide range of observation geometries and absorbers, as long as the dependency of the SCDs on wavelength is negligible within the fitting window.

\subsubsection{Limitations for measurements of scattered light}

For very long light paths or cases of strong absorption, however, it is found that the variability of the SCD in the fit window becomes important. For standard DOAS applications in satellite nadir geometry, this was first described by Diebel et al. (1995) and Richter (1997): For the retrieval of ozone VCDs from simulated spectra in a wavelength region between $335-346 \mathrm{~nm}$, a discrepancy of $\sim 2 \%$ for SZA significantly below $90^{\circ}$ and $\sim 15 \%$ for SZA near to $90^{\circ}$ was found with respect to the true column, if the wavelength dependence of the SCD is not taken into account.

The wavelength dependence of the SCD is caused by two effects:

(1) The slant path of scattered light varies with wavelength and the light path distribution changes (e.g. Solomon et al., 1987), since the Rayleigh-scattering cross-section varies as the inverse of the wavelength to the fourth power. Also, other scattering and reflection processes (on clouds, aerosols or ground) in the atmosphere are characterized by broad band functions of wavelength.

(2) SCDs vary across spectral structures of the trace gas absorption cross-sections because different light paths through the atmosphere also depend on the strength of the trace gas absorption (Platt et al., 1997; Marquard et al., 2000). Longer paths with stronger absorption have a smaller intensity and thus contribute less to the measurement than shorter paths with weaker absorption. Therefore the average path will be shorter and the SCD lower for stronger absorption. This effect becomes more pronounced for stronger absorption and when light crosses the atmosphere along very different trajectories. In contrast to the broad band scattering effect, the wavelength dependence caused by absorption can have a narrowband component of SCD variation because it depends on the absorption cross-sections of the absorbing trace gases.

Thus, the assumption of a wavelength and absorption independent SCD may lead to errors in the detection of all trace gases analyzed in a specific wavelength interval. In particular, neglecting the wavelength dependency for strong absorbers will affect the retrieval of minor absorbers. A more accurate description of the relation between vertical and slant column density should therefore take into account also the dependency on wavelength and vertical optical depth $v$ (Marquard et al., 2000):

$S_{i}=S_{i}(\lambda, v)=A_{i}(\lambda, v) \cdot V_{i}$

For a number of $k$ absorbers, the total vertical optical depth is the sum of the vertical optical depths of the individual absorbers:

$v=\sum_{i=1}^{k} V_{i} \sigma_{i}$

\subsubsection{AMFs for strong absorptions in limb geometry}

In limb geometry, light detected by the instrument arises from various locations along the LOS which has a length on the order of up to one thousand km through the Earth's atmosphere. Due to the wavelength dependency of the scattering and also the absorption processes, the length and the geometry of individual light paths differ significantly, resulting in a variation of the AMF (or the SCD) with wavelength for limb geometry much stronger than for nadir geometry.

Examples of AMFs for the wavelength region of 332$357 \mathrm{~nm}$ are illustrated in Fig. 1 for nadir (left panel) and limb (right panel) geometry for predefined atmospheric scenarios (parameters of the simulation are given in Table 1). The amplitudes of the AMF variations with respect to the mean value and their standard deviation are given in Table 2.

For nadir geometry at $\mathrm{SZA}=75^{\circ}$, the $\mathrm{AMF}$ varies within the fit window by about $3 \%$ (blue line in the left panel of the 
Table 1. Parameters used for the simulation studies.

\begin{tabular}{|c|c|c|c|}
\hline Parameter & Description of main settings & Settings for the AMF comparison & Settings for the sensitivity studies \\
\hline RTM model & \multicolumn{3}{|c|}{$\begin{array}{l}\text { Full spherical 3-D Monte Carlo RTM McArtim (Deutschmann, 2009). Simulations for } 10 \text { million photon trajectory } \\
\text { ensembles. Atmosphere discretized in } 1 \mathrm{~km} \text { layers up to } 100 \mathrm{~km} \text {. }\end{array}$} \\
\hline Atmosphere & \multicolumn{3}{|c|}{ Rayleigh atmosphere (i.e. without clouds and aerosols). } \\
\hline Ground albedo & \multicolumn{3}{|c|}{0.3} \\
\hline $\begin{array}{l}\text { Atmospheric profiles of } \mathrm{T}, \mathrm{p} \\
\text { and trace gases }\left(\mathrm{O}_{3}, \mathrm{NO}_{2}\right. \\
\text { and } \mathrm{BrO}) \text {. (Profiles of ozone } \\
\text { are provided in Fig. 2) }\end{array}$ & $\begin{array}{l}\text { Subarctic scenario corresponding } \\
\text { to Kiruna }\left(67.9^{\circ} \mathrm{N}\right) \text { in March, } \\
\text { ozone VCD of } 460 \mathrm{DU} \text {. }\end{array}$ & $\begin{array}{l}\text { Ozone profile also scaled to } 200 \mathrm{DU} \\
\text { (additionally to the main setting). }\end{array}$ & $\begin{array}{l}\text { Ozone profile also scaled to } 200 \mathrm{DU} \\
\text { (additionally to the main setting). } \\
\text { Additionally, tropical scenario, (ozone } \\
\text { VCD=270 DU, maximum concentration } \\
\text { of ozone at } 28 \mathrm{~km} \text { ). }\end{array}$ \\
\hline Geometry & $\begin{array}{l}\text { Geometry (SZA, SAA) from } \\
\text { SCIAMACHY orbit } 5545 \text { with } \\
\text { SZA at tangent point of } 75^{\circ} \text {, } \\
\text { SAA }=60^{\circ} .\end{array}$ & $\begin{array}{l}\text { Additionally: } \\
-\mathrm{AMFs} \text { at } \mathrm{SZAs} \text { of } 90^{\circ}, 88.5^{\circ} \text { and } \\
43^{\circ} \text { for nadir. } \\
\text { For limb geometry: } \\
\text { - AMFs at } \mathrm{SZAs}=88.5^{\circ} \\
-\mathrm{AMF} \text { for tropical scenario with } \\
\mathrm{SZA}=43^{\circ} \text { at tangent point }(\mathrm{TP}) \text {. } \\
\left(\text { For the case with } \mathrm{SZA}=43^{\circ}, \text { also }\right. \\
\text { ozone profile of } 200 \mathrm{DU} \text { is applied) }\end{array}$ & $\begin{array}{l}\text { Additionally to the main settings, } \\
\text { scenarios with } \mathrm{SZA}=43^{\circ} \text { at } \mathrm{TP} \text {. }\end{array}$ \\
\hline Wavelength region & $338-357 \mathrm{~nm}$. & $\begin{array}{l}\text { AMFs are studied in } 332-357 \mathrm{~nm} \\
\text { region. }\end{array}$ & $\begin{array}{l}\text { Different fit windows within the } \\
332-357 \mathrm{~nm} \text { region. }\end{array}$ \\
\hline
\end{tabular}

Table 2. Variation of AMFs of ozone in the wavelength range of 332-357 nm for different observation geometries and ozone profile with VCD of 460 DU (in brackets values for the scenario with VCD of ozone of 200 DU are given). The first number gives the difference between maximum and minimum values of AMFs normalized by the mean of AMFs in the wavelength range; the second number is the standard deviation. Calculations are performed only for selected geometries and SZAs in order to illustrate the general tendencies.

\begin{tabular}{lllll}
\hline SZA $\left({ }^{\circ}\right)$ & 90 & 88.5 & 75 & 43 \\
\hline nadir & $24 \% / 6.0 \%$ & $18 \% / 4.5 \%$ & $3.1 \% / 0.69 \%$ & $1.2 \% / 0.26 \%(1.2 \% / 0.32 \%)$ \\
Limb, TH=19.8 km & & $20 \% / 4.8 \%$ & $25 \% / 6.3 \%(18 \% / 4.8 \%)$ & $25 \% / 6.1 \%(18 \% / 4.6 \%)$ \\
Limb, TH=22.8 km & & $18 \% / 4.3 \%(12 \% / 3.1 \%)$ & \\
Limb, TH=35.9 km & & $9.5 \% / 2.0 \%(4.9 \% / 1.0 \%)$ & \\
\hline
\end{tabular}

Fig. 1), with a slight increase towards larger wavelengths. Additionally, at wavelengths, where absorption by ozone is stronger, AMFs are decreased by $\sim 2 \%$ at $334 \mathrm{~nm}$ because of the increased ozone absorption cross-section. For a SZA of $90^{\circ}$ (green line), however, the AMF increase for longer wavelengths is much stronger and the variation along the ozone absorption bands is more prominent, resulting in a variation of the AMFs in the fit window of around $25 \%$.

This strong dependency of the AMF on wavelength causes the discrepancies in the ozone retrieval described by Diebel et al. (1995) and Richter (1997).

Compared with the nadir viewing geometry, the variation with wavelength for limb geometry is one order of magnitude stronger for a scenario with $\mathrm{SZA}=75^{\circ}$ and the ozone VCD of 460 DU (solid red and cyan lines in the right panel of Fig. 1). The variation is around $25 \%$ with up to $\sim 10 \%$ decrease at the ozone absorption bands for a TH near the peak of the $\mathrm{BrO}$ and ozone profile.

A clear dependency of the AMF of ozone on its optical depth is observed: For an ozone profile with a VCD of 460 DU (solid red and cyan lines in the plot) the AMFs decrease in comparison to the ozone profile scaled to a VCD of $200 \mathrm{DU}$ (dashed red and cyan lines). The difference is stronger for those wavelengths where the absorption crosssection of ozone is larger. The ozone profiles applied for the simulations are plotted in Fig. 2.

Due to the long light paths for limb geometry and the resulting large differences of the light paths, the strong variation of the AMF with wavelength occurs already for low SZAs.

For nadir geometry the lengths of the light paths increase strongly only at high SZAs (i.e., at SZAs close to $90^{\circ}$ ). As 

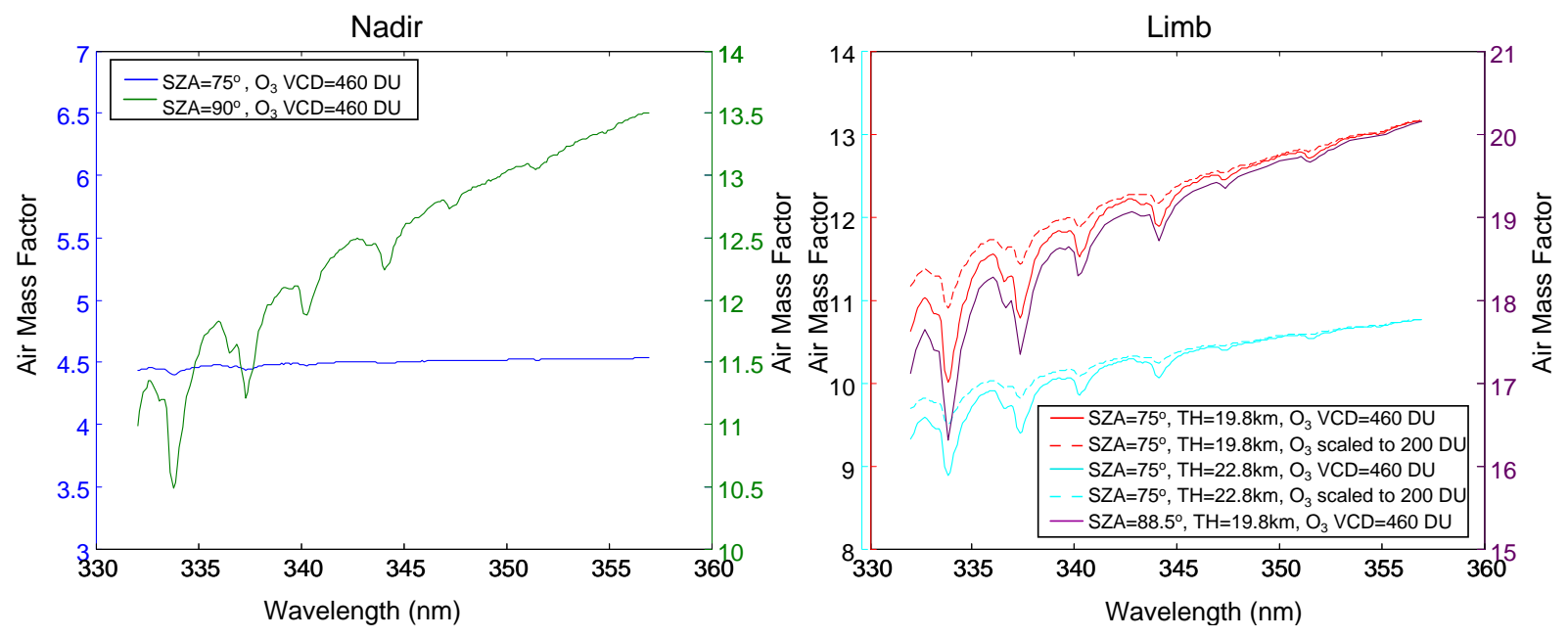

Fig. 1. AMFs of ozone for nadir (left) and limb geometry (right) as function of wavelength for different atmospheric scenarios (see legend and Table 1 for details).

a result, for nadir observations, only a small part of all satellite measurements is affected by large discrepancies. In contrast, for limb geometry light paths are much longer, resulting in larger differences between light paths. Consequently a strong variation of the AMF with wavelength occurs already at small SZA. Hence, every limb measurement is affected significantly.

\subsection{A new approach for accounting for the variability of SCDs and AMFs in the DOAS fit}

In the following, we introduce a new approach to take into account the spectral dependency of the SCD or AMF on wavelength in the DOAS fit, and thereby to minimize the associated retrieval error. As summarized above (see Sects. 2.1.2 and 2.1.3), the wavelength dependency of the SCD and the AMF results from scattering and absorption processes (Eq. 3). Both processes can be described by a broad band function of wavelength and/or the vertical optical depth (which itself shows a narrow band variation on wavelength). Thus, it is reasonable to formulate the SCD or the AMF as a function of wavelength and vertical optical depth. The Taylor series expansion for such a function generally can be written as:

$$
F(\lambda, v)=\sum_{n=0}^{\infty} \sum_{m=0}^{\infty} \frac{\partial^{n} \partial^{m}}{\partial \lambda^{n} \partial v^{m}} \frac{F(w, d)}{n ! m !}(\lambda-w)^{n}(v-d)^{m}
$$

$F(\lambda, v)$ can be either the SCD or AMF at wavelength $\lambda$ and vertical optical depth $v$ being approximated around wavelength $w$ and vertical optical depth $d . n$ and $m$ is the order of derivation with respect to wavelength $\lambda$ and vertical optical depth $v$, respectively.

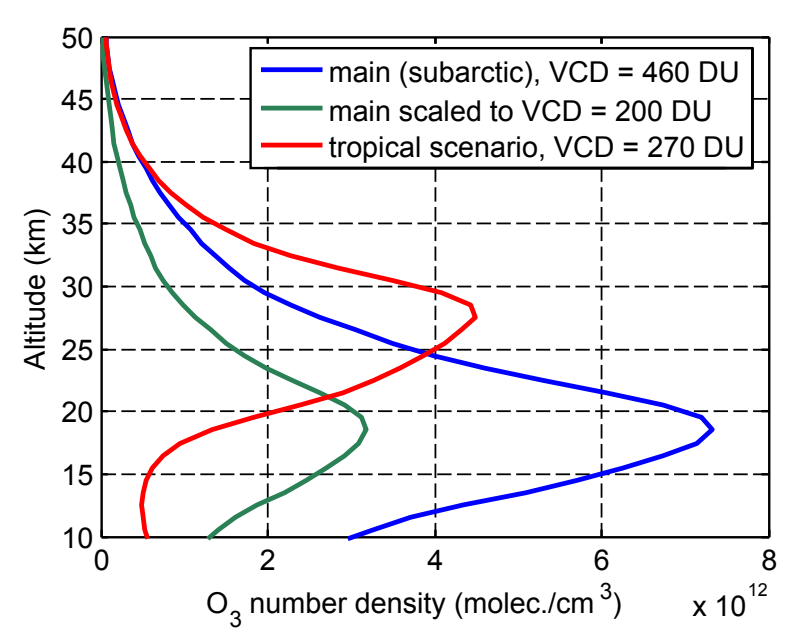

Fig. 2. Different ozone profiles applied for the simulation of spectra, air mass factor calculations and sensitivity studies.

When taking into account the terms up to the 1 st order, the wavelength and optical depth dependent SCD is described by:

$S(\lambda, v) \approx S_{0}^{*}(w, d)+S_{\lambda}(w, d) \lambda+S_{v}(w, d) v$

where the subscripts indicate the quantity with respect to which the partial derivatives are performed and $S_{0}^{*}(w, d)$ is the sum of the 0 -th order terms:

$S_{0}^{*}(w, d)=S_{0}-S_{\lambda} \cdot w-S_{v} \cdot d$

When considering the vertical optical depth of only the strongest absorber $s$, e.g. ozone (assuming that the minor absorbers cause only negligible contributions to the vertical 
Table 3. Relation of the spectral quantities with Eq. (5) and to each other.

\begin{tabular}{|c|c|c|c|}
\hline & $\begin{array}{l}\text { Slant column } \\
\text { density }\end{array}$ & $\begin{array}{l}\text { Air mass fac- } \\
\text { tor }\end{array}$ & Optical depth \\
\hline Relation with SCD & $S(\lambda)$ & $\frac{S(\lambda)}{V}$ & $S(\lambda) \cdot \sigma(\lambda)$ \\
\hline Relation with AMF & $A(\lambda) \cdot V$ & $A(\lambda)$ & $A(\lambda) \cdot V \cdot \sigma(\lambda)$ \\
\hline Relation with opti- & $\frac{\tau(\lambda)}{\sigma(\lambda)}$ & $\frac{\tau(\lambda)}{V \cdot \sigma(\lambda)}$ & $\tau(\lambda)$ \\
\hline Relation with VCD & $V \cdot A(\lambda)$ & $\frac{S(\lambda)}{V}$ & $V \cdot A(\lambda) \cdot \sigma(\lambda)$ \\
\hline Relation with verti- & $\frac{v(\lambda) \cdot A(\lambda)}{\sigma(\lambda)}$ & $\frac{\tau(\lambda)}{v(\lambda)}$ & $v(\lambda) \cdot A(\lambda)$ \\
\hline $\begin{array}{l}\text { Relation with inten- } \\
\text { sity }\end{array}$ & $\frac{\ln \frac{I_{a}(\lambda)}{I(\lambda)}}{\sigma(\lambda)}$ & $\frac{\ln \frac{I_{a}(\lambda)}{I(\lambda)}}{\sigma(\lambda) \cdot V}$ & $\ln \frac{I_{a}(\lambda)}{I(\lambda)}$ \\
\hline & \multicolumn{3}{|c|}{$\begin{array}{l}\left(I(\lambda)-\text { intensity, } I_{a}(\lambda)-\text { intensity without the }\right. \\
\text { absorber of interest })\end{array}$} \\
\hline $\begin{array}{l}\text { Relation with Tay- } \\
\text { lor series expansion } \\
\text { in Eq. (5) }\end{array}$ & $F(\lambda)$ & $F(\lambda)$ & $F(\lambda) \cdot \sigma(\lambda)$ \\
\hline
\end{tabular}

optical depth), the last term of Eq. (6) becomes (compare with Eq. 4 when $k=1$ ):

$S_{v} v \approx \underbrace{S_{v} \overbrace{V_{s}}^{v_{s}} \sigma_{s}}_{S_{s}}=S_{s} \sigma_{s}$

where $S_{s}$ is the product of $S_{v}$ and the VCD of the absorber $s$, and $\sigma_{s}$ its cross-section.

Thus Eq. (6) becomes:

$S(\lambda, v) \approx S_{0}^{*}(w, d)+S_{\lambda}(w, d) \lambda+S_{S}(w, d) \sigma_{s}$

In the DOAS equation, the optical depth of a particular trace gas is a product of its SCD and cross-section $\sigma$. Therefore, the optical depth for an absorber $a$ according to Eq. (9) is:

$\tau_{a}(\lambda, v) \approx S_{0, a}^{*} \sigma_{a}+S_{\lambda, a} \lambda \sigma_{a}+S_{s, a} \sigma_{s} \sigma_{a}$

Parameters $S_{0, a}^{*}, S_{\lambda, a}$ and $S_{s, a}$ are functions linearized at arbitrary wavelength $w$ and vertical optical depth $d$, and are determined by a common least squares DOAS fit. The total wavelength dependent SCD $S$ of the considered absorber then results from Eq. (9).

If we consider only the absorption of the strong absorber (i.e. $s=a$ ) and write Eq. (10) for the optical depth of this absorber, it becomes:

$\tau_{s}(\lambda, v) \approx S_{0, s}^{*} \sigma_{s}+S_{\lambda, s} \lambda \sigma_{s}+S_{s, s} \sigma_{s}^{2}$

Because the vertical optical depths of minor absorbers cause only negligible contributions to the total optical depth, it is necessary to consider the wavelength dependency of the SCD only for strong absorbers in practice. For example, in Sect. 3 we show that the DOAS retrieval of $\mathrm{BrO}$ is improved considerably when including the first order terms according to Eqs. (6) and (11) for the ozone SCD in the spectral analysis (in the following, this first order approximation is referred to as the Taylor series approach). Taking into account the wavelength dependency of the SCDs also for minor absorbers further improves the retrieval (see Appendix C).

The mathematical relations for the spectroscopic quantities SCD, AMF and optical depth are summarized in Table 3. In Appendix A we show that the AMF (and thus also SCD) can be approximated by the Taylor series approach up to a precision on the order of the simulation error of the AMFs. If the absorption of minor absorbers is not accounted for, the approximation of AMFs is improved by one order of magnitude in the fit window of $338-357 \mathrm{~nm}$.

\section{Application of the Taylor series approach to DOAS retrieval from simulated spectra}

In the following, we compare the new retrieval approach to standard DOAS and the AMF modified DOAS by performing the DOAS fit i.e. retrieving SCDs of several absorbing trace gases (ozone, $\mathrm{BrO}$ and $\mathrm{NO}_{2}$ ) from simulated spectra.

For the study, we apply spectra simulated by the RTM McArtim with the main settings provided in Table 1, corresponding to the SCIAMACHY limb scanning sequence on 23 March 2003 over Kiruna with a SZA of $75^{\circ}$ at the tangent point (TP). The output of the RTM is the sun normalized radiance, $I / I_{0}$. The wavelength range of $338-357 \mathrm{~nm}$, which is employed in our standard retrieval algorithm for $\mathrm{BrO}$, is used, for details see Kühl et al. (2008).

The standard DOAS approach for the absorption of ozone, $\mathrm{NO}_{2}$ and $\mathrm{BrO}$ according to Eq. (1) is:

$\ln \frac{I_{0}}{I}=S_{\mathrm{O}_{3}} \sigma_{\mathrm{O}_{3}}+S_{\mathrm{NO}_{2}} \sigma_{\mathrm{NO}_{2}}+S_{\mathrm{BrO}} \sigma_{\mathrm{BrO}}+P$

In the considered UV spectral range the absorption by ozone dominates. Taking into account the first order Taylor series expansion for this strong absorber $\left(s=\mathrm{O}_{3}\right.$ in Eqs. 9 and 11), the DOAS equation becomes:

$$
\begin{aligned}
& \ln \frac{I_{0}}{I}=\underbrace{S_{0, \mathrm{O}_{3}}^{*} \sigma_{\mathrm{O}_{3}}+S_{\lambda, \mathrm{O}_{3}} \lambda \sigma_{\mathrm{O}_{3}}+S_{\mathrm{O}_{3}, \mathrm{O}_{3}} \sigma_{\mathrm{O}_{3}}^{2}}_{\tau_{\mathrm{O}_{3}}} \\
& +S_{\mathrm{NO}_{2}} \sigma_{\mathrm{NO}_{2}}+S_{\mathrm{BrO}} \sigma_{\mathrm{BrO}}+P
\end{aligned}
$$

In the common DOAS least squares fit of SCDs, the difference between the left and right side of the equation is minimized for all wavelengths. Slant column densities of $\mathrm{NO}_{2}$ and $\mathrm{BrO}\left(\mathrm{S}_{\mathrm{NO}_{2}}\right.$ and $\left.S_{\mathrm{BrO}}\right)$ are fitted as wavelength independent in the study. The wavelength dependent SCD of ozone is 
Table 4. Fit terms describing the trace gas absorptions for different approaches in the DOAS fit.

\begin{tabular}{llll}
\hline \multicolumn{4}{c}{ trace gas } \\
\hline Method & Ozone & $\mathrm{BrO}$ & $\mathrm{NO}_{2}$ \\
\hline Standard DOAS & $S_{\mathrm{O}_{3}} \sigma_{\mathrm{O}_{3}}$ & $S_{\mathrm{BrO}} \sigma_{\mathrm{BrO}}$ & $S_{\mathrm{NO}_{2} \sigma_{\mathrm{NO}_{2}}}$ \\
Taylor series approach for ozone $\mathrm{SCD}$ & $S_{0_{3} \mathrm{O}_{3}} \sigma_{\mathrm{O}_{3}} ; S_{\lambda, \mathrm{O}_{3}} \lambda \sigma_{\mathrm{O}_{3}} ; S_{\mathrm{O}_{3}, \mathrm{O}_{3}} \sigma_{\mathrm{O}_{3}}^{2}$ & $S_{\mathrm{BrO}} \sigma_{\mathrm{BrO}}$ & $S_{\mathrm{NO}_{2}} \sigma_{\mathrm{NO}_{2}}$ \\
AMF modified DOAS for ozone & $V_{\mathrm{O}_{3} A_{\mathrm{O}_{3}} \sigma_{\mathrm{O}_{3}}}$ & $S_{\mathrm{BrO}} \sigma_{\mathrm{BrO}}$ & $S_{\mathrm{NO}_{2}} \sigma_{\mathrm{NO}_{2}}$ \\
\hline
\end{tabular}

acquired from the fitted coefficients $S_{0, \mathrm{O}_{3}}, S_{\lambda, \mathrm{O}_{3}}$ and $S_{\mathrm{O}_{3}, \mathrm{O}_{3}}$ according to Eq. (9).

Alternatively for comparison we apply also the AMF modified DOAS method (according to Diebel et al., 1995; Richter, 1997) where the variation of the ozone SCD in the fit window is described by the AMF:

$\ln \frac{I_{0}}{I}=\underbrace{V_{\mathrm{O}_{3}} A_{\mathrm{O}_{3}}}_{S_{\mathrm{O}_{3}}} \sigma_{\mathrm{O}_{3}}+S_{\mathrm{NO}_{2}} \sigma_{\mathrm{NO}_{2}}+S_{\mathrm{BrO}} \sigma_{\mathrm{BrO}}+P$

Here the VCD of ozone is acquired directly by fitting the $A_{\mathrm{O}_{3}} \sigma_{\mathrm{O}_{3}}$ term (where the AMFs should be calculated for every wavelength in advance for an a priori scenario). The SCD is obtained as the product of the fitted VCD and the AMFs used for the fit.

Table 4 summarizes the terms used for the description of the optical depth by the different approaches.

\subsection{Improvement for the retrieval of ozone SCDs}

Since the new Taylor series approach is applied for the SCDs of ozone, we first investigate in how far the improved description of the wavelength dependency of the ozone SCDs (Eq. 14) results in an improvement for the fit. Later we study also the related improvement for the fit of the weak absorber $\mathrm{BrO}$ (Sect. 3.2).

Figure 3 shows the relative deviation of the fitted SCDs of ozone from the true values simulated by the RTM for selected THs (19.8 and $22.8 \mathrm{~km}$, near the peak of the BrO profile). Included are the results for the Taylor series approach, the standard DOAS and the AMF modified DOAS (Eqs. 12-14).

The standard DOAS approach, which neglects the variation of the ozone SCD in the fit window, gives more than $10 \%$ underestimation at some wavelengths with respect to the true values of the SCDs (dashed lines in Fig. 3). This difference reflects the variability of the AMFs in the fit window discussed in the section before. The discrepancy is largest at longer wavelengths (outside the strong absorption bands) because the DOAS fit is more constrained by wavelength regions with strong variations of the cross-section (see e.g. Marquard et al., 2000).

In comparison, the novel approach for the parameterization of the SCDs of ozone by the Taylor series approach improves the retrieval significantly (see solid lines in Fig. 3):

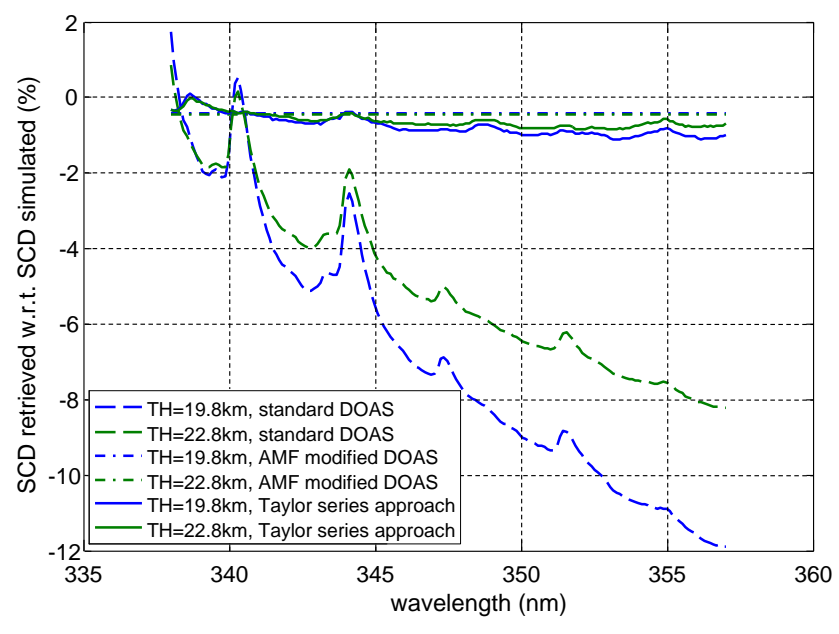

Fig. 3. Relative difference between the retrieved and the true (simulated) ozone SCDs using different approaches. Plots are for two THs near the peak of the $\mathrm{BrO}$ profile (19.8 and $22.8 \mathrm{~km}$ ). The same relative differences are valid also for the relation between fitted and true optical depths.

the deviation from the true value is only $1.5 \%$ at maximum at the longer wavelength edge of the fit window. Similarly as for the description of the AMFs in Appendix A, the improvement is one order of magnitude, compared with the standard approach. These results indicate that the approach allows to account much better for the wavelength variation of the ozone SCD in the fit window, even without knowledge of the ozone AMFs. The remaining negative discrepancy and the structures at the $\mathrm{BrO}$ absorption peaks in the figure can be explained by unfitted higher order terms and the impact of minor absorbers on the ozone SCD (compare Appendix A).

The AMF modified DOAS also gives a good agreement with a discrepancy of $0.5 \%$ (see dash-dotted lines in Fig. 3). This small disagreement probably arises from the interference with the absorption structures of the minor absorbers because the variation of their SCDs with wavelength is not accounted for in the fit. Note that for this retrieval AMFs calculated for the same parameters as the model scenario were applied. Therefore, in real applications, when the atmospheric scenario is not known beforehand, larger discrepancies may be expected. 


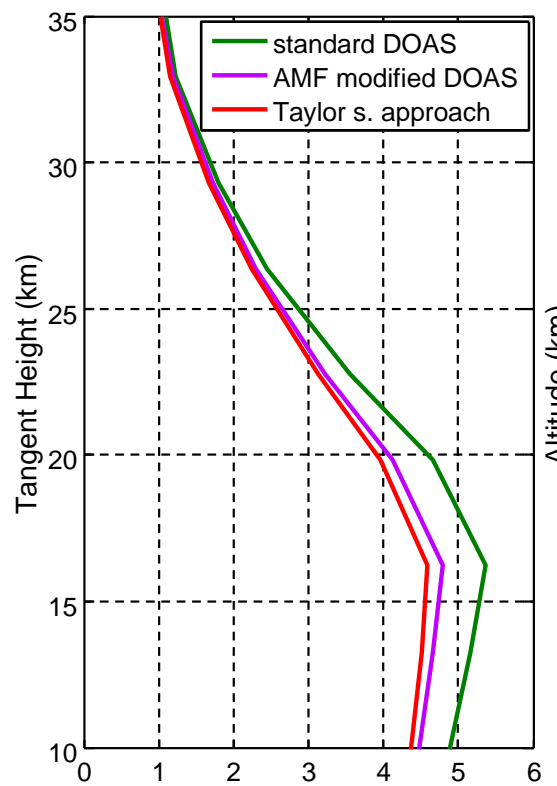

Slant column density $\left(\times 10^{14}\right.$ molec. $\left./ \mathrm{cm}^{2}\right)$
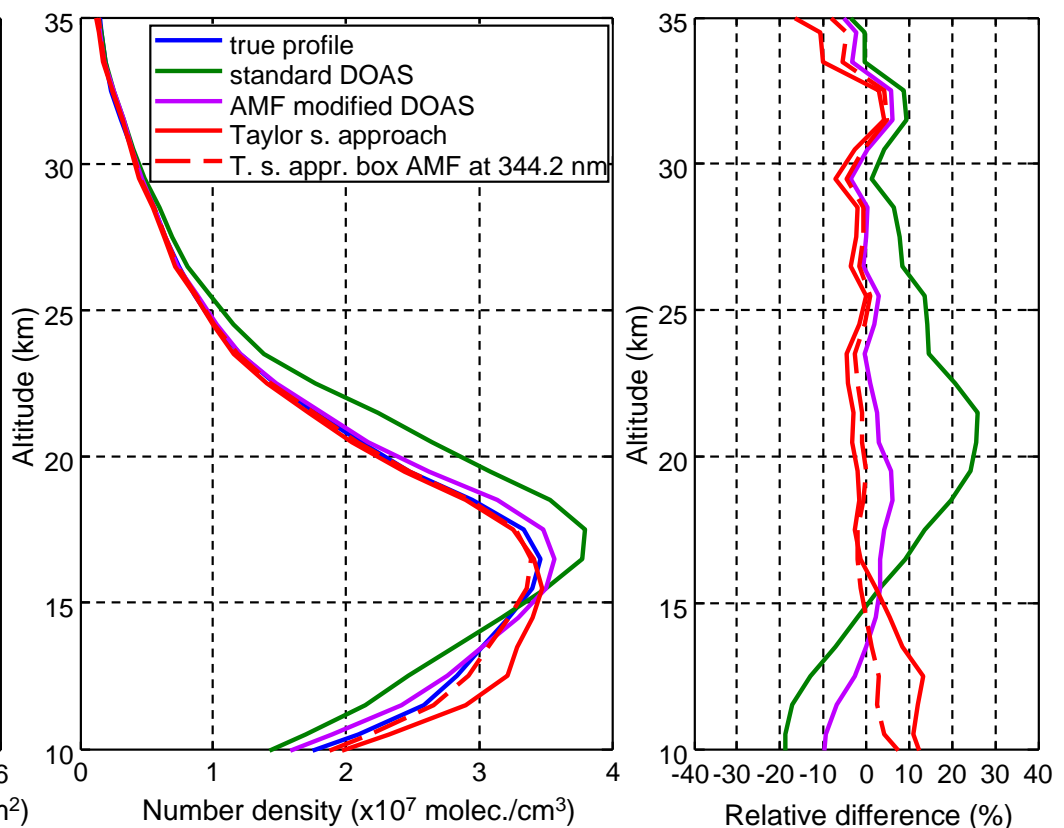

Fig. 4. BrO SCDs (left panel) and the vertical concentration profiles (middle panel) retrieved by different approaches (green: standard DOAS, violet: AMF modified DOAS, red: Taylor series approach, dashed red: AMFs for the Taylor series approach evaluated at a single wavelength of $344.2 \mathrm{~nm}$ ). The right panel shows the relative difference of the retrieved profiles to the true concentration profile applied for the simulation.

At certain wavelengths the discrepancy of the SCD retrieved by the standard DOAS with the true SCD is much smaller than $10 \%$, for wavelengths around $340 \mathrm{~nm}$, even an agreement can be found. Although this agreement cannot be extrapolated for every scenario, it is possible to retrieve a rather accurate ozone profile by applying the AMF for the wavelength region with the smallest discrepancy. Thus the introduced Taylor series approach would not always be necessary for the ozone profile retrieval. However, the unfitted ozone absorption structures that arise from not taking into account the wavelength dependency of the ozone SCD cause large errors in the retrieval of minor absorbers as is shown in detail in the following section.

\subsection{Improvement for the retrieval of $\mathrm{BrO}$}

In the following, we show that the improvement in the ozone SCD retrieval by the Taylor series approach results also in an improvement of the BrO SCD retrieval (Sect. 3.2.1) and therefore in a much better agreement of the retrieved $\mathrm{BrO}$ vertical profile with the true simulated profile, compared to standard DOAS (Sect. 3.2.2).

\subsubsection{Slant column density of BrO}

For the same scenario and spectra as in Sect. 3.1, we now investigate the values retrieved for the BrO SCDs by the three approaches (i.e. standard DOAS, Taylor series approach for the SCDs of ozone, and AMF modified DOAS for ozone), see Fig. 4 (left panel). The values for standard DOAS (green line) are by up to $15 \%$ larger compared to the Taylor series approach (red line) or AMF modified DOAS (magenta line). This can be explained by unfitted structures in the fit residual (see Fig. 5) that increase the retrieval error for the standard DOAS approach: As illustrated in Fig. 5, residual structures around the ozone absorption bands occur because the variation of the SCD of ozone within the fit window is not taken into account. These ozone specific absorption structures remain because they are not (completely) allocated to other fit parameters. However, misallocation of some optical depth of ozone to BrO takes place: The underestimation of the SCD (or optical depth) of ozone at the absorption bands of $\mathrm{BrO}$ (compare e.g. SCD of ozone at $338 \mathrm{~nm}$, where the strongest BrO absorption band occurs, in Fig. 3) leads to an overestimation of the retrieved SCDs of BrO in the standard DOAS. This dependency of the retrieved BrO SCDs on ozone absorption is investigated in more detail in Appendix C.

On the other hand, both the Taylor series approach and AMF modified DOAS reduce the residual structures by one order of magnitude (see Fig. 5, bottom panel). Therefore also the error of the fit is reduced significantly. The reason for these improvements is that the optical depth variation of ozone is described better for the whole fit window. Accordingly, BrO SCDs retrieved by both methods agree well with the simulated $\mathrm{BrO}$ SCDs at wavelengths close to 

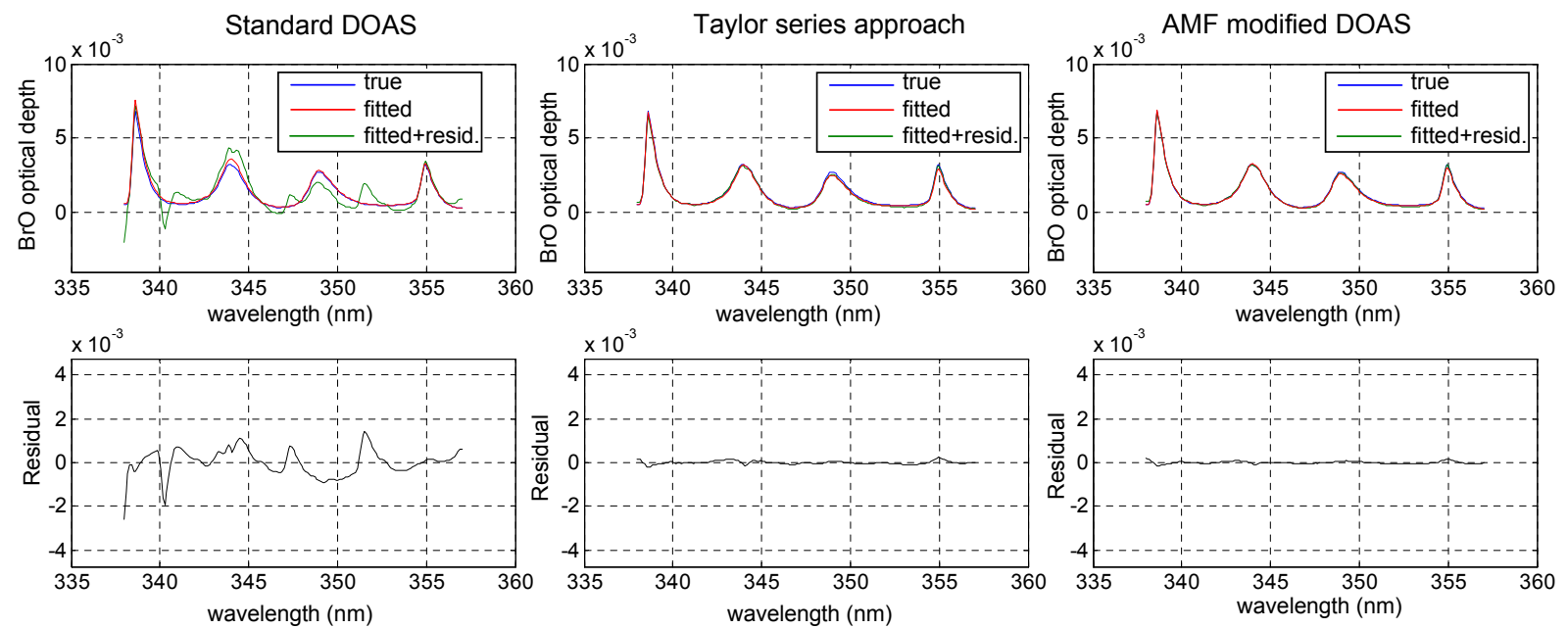

Fig. 5. Left panel: Retrieved optical depth of $\mathrm{BrO}$ for $\mathrm{TH}=22.8 \mathrm{~km}$ by the standard DOAS fit. Middle panel: same but for the Taylor series approach. Right panel: same but for AMF modified DOAS for ozone. Top panels show the true optical depth of BrO (blue), fitted optical depth of $\mathrm{BrO}$ (red) and the optical depth plus residual structures (green). The bottom panels show the residuals alone.

the strongest absorption peaks of $\mathrm{BrO}$, and the discrepancy shows only negligible influence by ozone absorption (see also Appendix C).

\subsubsection{Improvement for the retrieved $\mathrm{BrO}$ profile}

In the next step, the $\mathrm{BrO}$ profile is determined by inversion of the BrO SCDs. For this purpose, we apply our general retrieval algorithm based on the linear optimal estimation method (Rodgers, 2000) and described in detail in Puķīte et al. (2006) and Kühl et al. (2008). The a priori settings are selected assuring that the measurement response (i.e., the sum of the rows of the averaging kernel matrix) is close to unity at altitudes between 13 to $35 \mathrm{~km}$ for all of the three approaches (standard DOAS, Taylor series approach and AMF modified DOAS), i.e. thereby minimizing the impact of a priori assumptions. To achieve this, an a priori profile as $2 / 3$ of the true profile is used, with an a priori uncertainty of $100 \%$ of its maximum value. The retrieval is performed on a $1 \mathrm{~km}$ altitude grid. For smoothing purposes, a correlation length (see Rodgers, 2000, page 38) of $3.5 \mathrm{~km}$ is introduced in the a priori covariance matrix. With these settings, the impact of the a priori is minimized for this altitude range so that even a shift of the a priori profile by $3 \mathrm{~km}$ downwards results in less than $\sim 2 \%$ differences in retrieved profiles both for the Taylor series approach and AMF modified DOAS, and less than $\sim 5 \%$ changes for the standard DOAS.

Box AMFs for the inversion are calculated for the same atmospheric conditions as the simulated spectra, in order to limit related systematical retrieval errors in the comparison of the three approaches. Box AMFs are derived by a weighted average calculated at different wavelengths based on an approach by Marquard et al. (2000) that the fit is constrained stronger by absorption structures that vary more rapidly with wavelength. An alternative retrieval is performed with box AMFs calculated at a single wavelength of $344.2 \mathrm{~nm}$. At this wavelength, the retrieved BrO SCDs agree with the true SCDs of $\mathrm{BrO}$ within $\sim 3 \%$ for different ozone profiles as it is deduced from sensitivity studies, see e.g. Fig. C1, second panel from top, in the Appendix C.

The obtained vertical concentration profiles are shown together with the true profile in Fig. 4 (middle panel), the difference is plotted in the right panel. The profile retrieved from SCDs acquired by standard DOAS shows a shift upwards (by $\sim 1.5 \mathrm{~km}$ ) and too large values at the peak by $\sim 10 \%$. The overestimation above the peak is more than 20 or $25 \%$ for altitudes with large ozone concentration, i.e. around $20 \mathrm{~km}$ (compare with Fig. 2). On the other hand, the profile obtained by AMF modified DOAS or the Taylor series approach agrees much better with the true profile. For altitudes between 15 and $28 \mathrm{~km}$ the agreement for the Taylor series approach is better than $5 \%$. For altitudes below $15 \mathrm{~km}$ the discrepancy increases to $\sim 10 \%$ (note that below $12 \mathrm{~km}$ the measurement response is very low).

Thus, although the wavelength dependency of the SCDs of minor absorbers is not taken into account, the retrieval of $\mathrm{BrO}$ is improved considerably by taking the variability of the SCD of ozone in the fit window into consideration.

The disagreement around altitudes of $19 \mathrm{~km}$ for the AMF modified DOAS and the slightly lower values for the Taylor series approach probably arise from the interference with the absorption structures of the minor absorbers (note that both AMF modified DOAS and the Taylor series DOAS are performed only for the SCD of ozone).

The red dashed line in Fig. 4 shows the profile obtained by inversion of the SCDs acquired by the Taylor series approach, when box AMFs calculated at a single wavelength $(344.2 \mathrm{~nm})$ are applied. This also shows a good agreement 


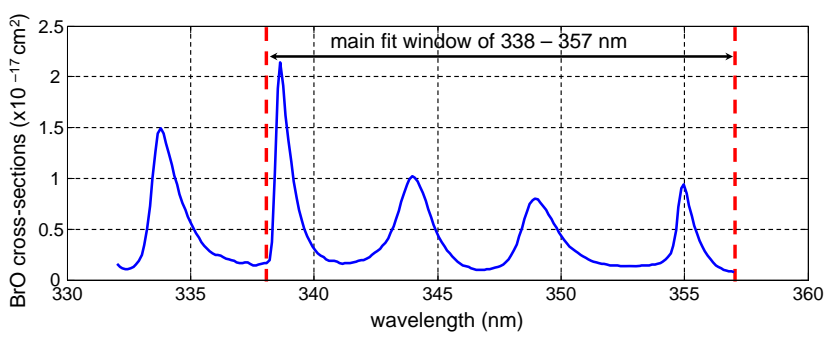

Fig. 6. BrO absorption cross-section (Fleischmann et al. (2004)) used for simulations of spectra, convoluted to SCIAMACHY resolution of FWHM of $0.21 \mathrm{~nm}$. In the main settings the fit window from $338-357 \mathrm{~nm}$ is applied (indicated by red lines in the plot). For the sensitivity studies, different fit windows containing 2-5 $\mathrm{BrO}$ absorption peaks within the wavelength region from $332-357 \mathrm{~nm}$ are investigated.

within 3\% for most altitudes (compare also sensitivity studies in Appendix C).

It should be noted that all discussed methods can use an iterative scheme in order to improve the profile retrieval, e.g., by applying the retrieved information for the calculation of AMFs or weighting functions in the next iteration step.

\section{Sensitivity studies with simulated spectra}

The previous section revealed that the Taylor series approach for the ozone SCD significantly improves the retrieval both for ozone and for the minor absorber $\mathrm{BrO}$ for the fit window of $338-357 \mathrm{~nm}$. The agreement with the true (simulated) values is better and the fit quality increases, which is reflected by reduced fit residual. This was shown for a subarctic atmospheric scenario with a relatively strong absorption of ozone ( $\mathrm{VCD}=460 \mathrm{DU})$.

In this section we investigate the new retrieval approach for different fit windows (see Sect. 4.1) and for different absorption strengths of ozone and $\mathrm{BrO}$ by assuming different atmospheric profiles (Sect. 4.2).

Additionally, in Appendix C, we present a study of the possibility to describe also the SCDs of the minor absorber BrO by Taylor series terms.

\subsection{Application of the method to different fit windows}

Since the strength of absorption and the scattering probability in the atmosphere vary with wavelength, the improvement of the retrieval by the Taylor series approach with respect to standard DOAS may be different for fit windows covering various wavelength ranges.

We investigate the applicability of the approach for different fit windows in the range from $332-357 \mathrm{~nm}$ where $\mathrm{BrO}$ absorption is largest (see Fig. 6).

We perform the DOAS retrieval considering various parameters of the Taylor series: either including all three terms of ozone optical depth in Eq. (14); accounting only for the broad band wavelength dependency (by the first and the second term in the equations); or considering only the narrow band dependency due to the ozone absorption structures (by the first and the third term). For comparison, we also apply the standard DOAS retrieval. The focus here is on the $\mathrm{BrO}$ retrieval, the impact on the ozone SCD is explored for the fit window of 338-357 $\mathrm{nm}$ in Appendix B.

The study is performed for all possible combinations of fit windows with $2-5 \mathrm{BrO}$ absorption peaks. The fit windows and the retrieved $\mathrm{BrO}$ profiles are depicted in Fig. 7. A comparison of the quality of the profiles retrieved by the different methods is given in Table 5.

Standard DOAS: Summarizing the results, standard DOAS (green lines in Fig. 7) gives better results for fit windows that do not include the first absorption peak of $\mathrm{BrO}$ at $334 \mathrm{~nm}$ because otherwise large retrieval errors (due to large structures in the residuals) are obtained. If only two absorption bands are considered (plots on the far right), the error decreases if the bands at larger wavelengths are included in the fit due to the decrease in ozone absorption. Therefore, very good agreement for standard DOAS is obtained only for the fit window $347.8-357 \mathrm{~nm}$ (see the plot in the bottom panel).

Taylor series approach: The retrieved $\mathrm{BrO}$ profile (red lines in the Fig. 7) is considerably improved compared with the standard DOAS. Only small discrepancies (not much larger than 5\%) are found for the fit windows starting at shorter wavelengths, probably because of the small effect of minor trace gases on the optical depth of ozone.

The agreement is best for either very large fit windows (332-357 nm and 332-351.1 nm, first and second plots from left at the top in the figure), or for fit windows at longer wavelengths where ozone absorption is smaller (those starting at $341.3 \mathrm{~nm}$, see last two panels at the bottom of Fig. 7).

Separate terms of Taylor series approach: Some improvement is already gained with respect to standard DOAS if only either the wavelength dependency term $\left(S_{\lambda, \mathrm{O}_{3}} \lambda \sigma_{\mathrm{O}_{3}}\right)$ or the cross-section dependency term $\left(S_{\mathrm{O}_{3}, \mathrm{O}_{3}} \sigma_{\mathrm{O}_{3}}^{2}\right)$ for the optical depth of ozone is included in the analysis (green and brown dashed lines in Fig. 7, respectively). In particular, a good agreement with the true profile is found for cases when only the wavelength term is considered for the fit windows with the lower boundary at or above $338 \mathrm{~nm}$ (see plots in the last panels at the top of the figure). For fit windows including the much stronger ozone absorption band at $334 \mathrm{~nm}$ (plots in the top panel), however, the consideration of the cross-section term in describing the ozone SCDs is important in order to retrieve correct values for the $\mathrm{BrO}$ concentration. Neglecting this term can lead to errors of up to $20 \%$.

In summary, the Taylor series approach allows to extend the application of DOAS to any studied fit window without the necessity to include a priori information for the AMF calculation. a priori assumptions in general may differ strongly from reality, especially regarding scattering processes in the 

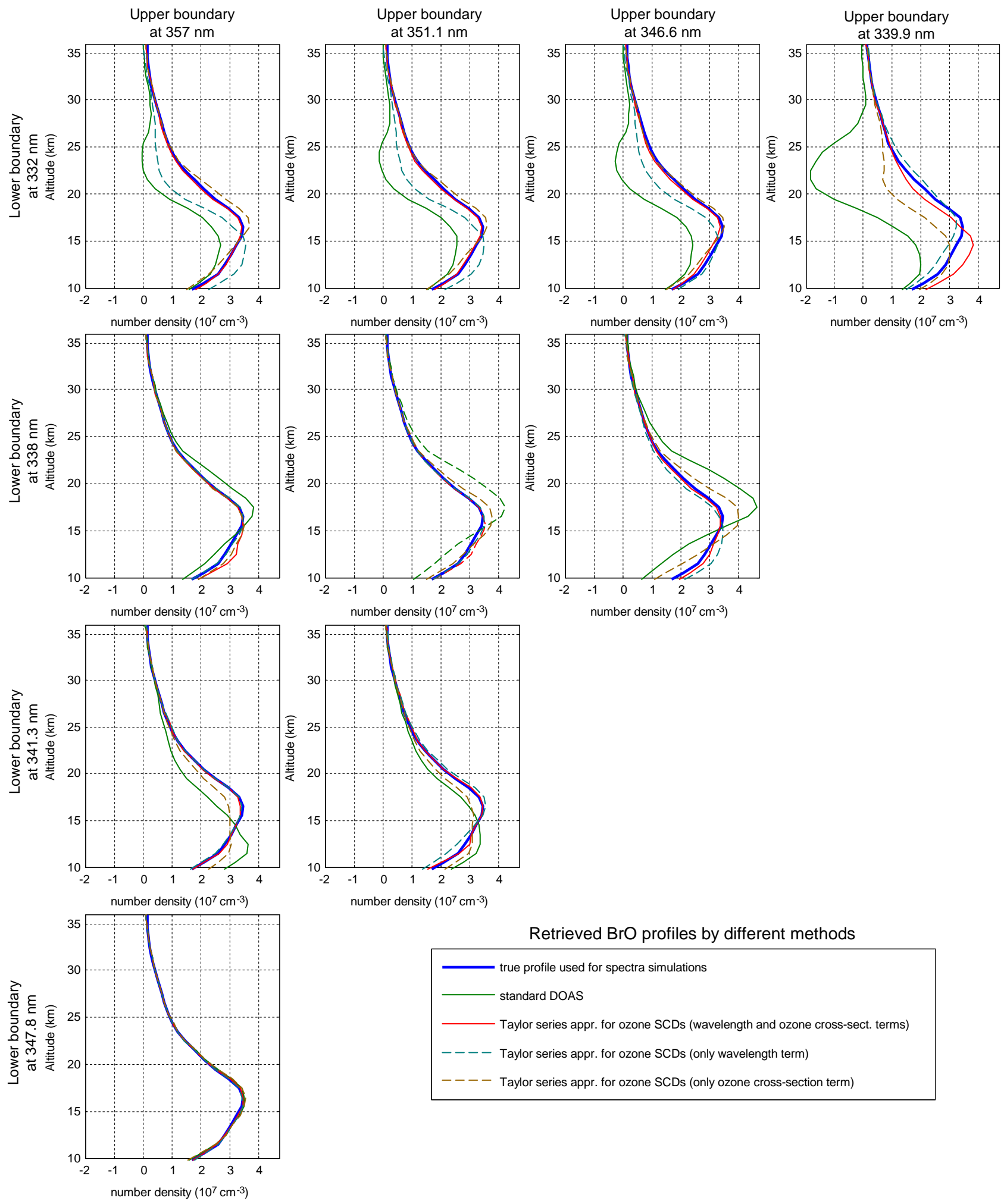

Fig. 7. Vertical profiles of the BrO number density retrieved from the simulated spectra for different fit windows and different retrieval approaches. Plots in the same row correspond to the same lower boundary of the fit window, plots in the same column to the same upper boundary of the fit window. 
Table 5. Characterization of the BrO retrieval results obtained by different methods and applying different fit windows. Text in bold indicates good agreement, text in italic significant disagreement.

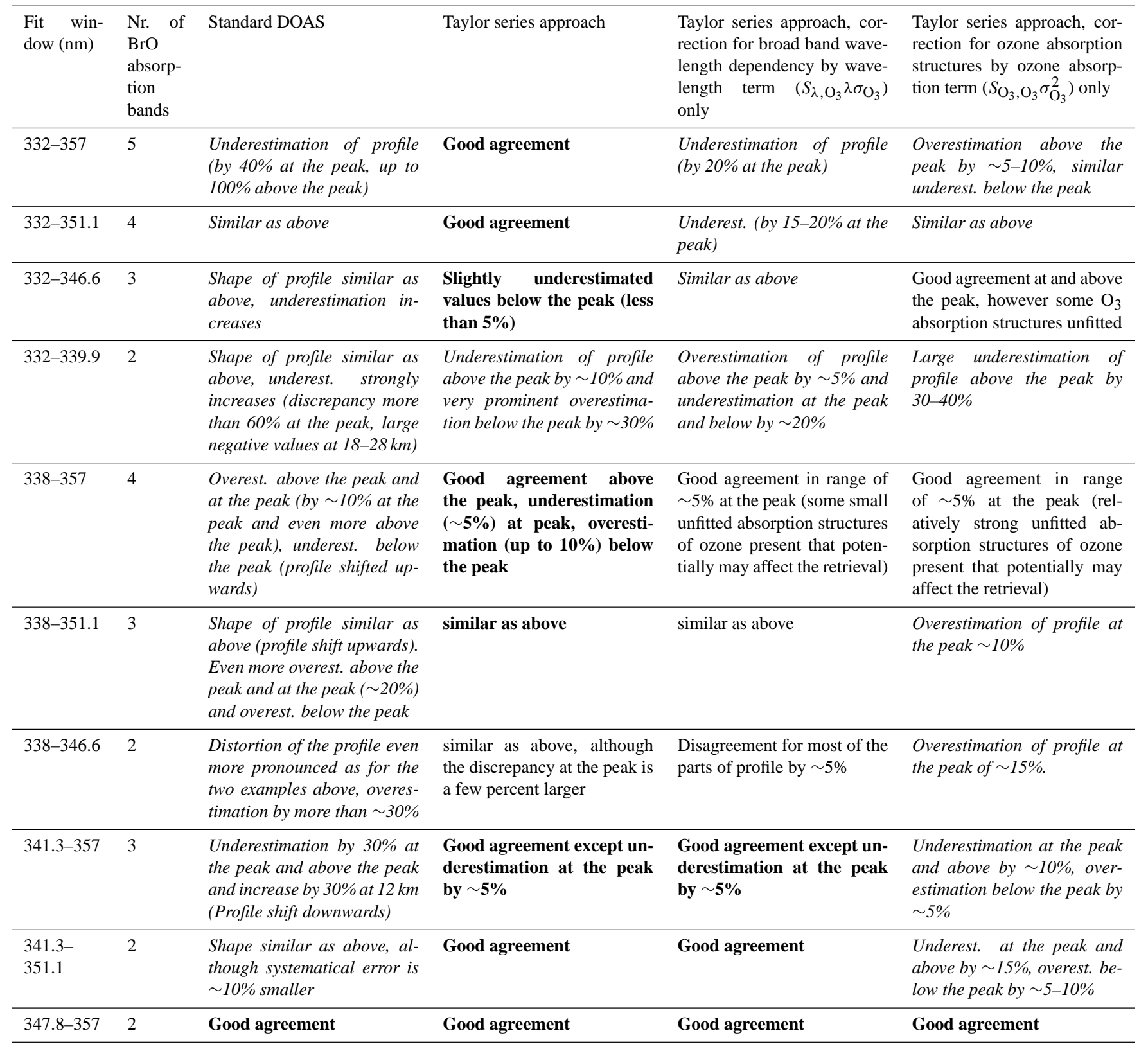

atmosphere (e.g., clouds, aerosols, temperature and pressure).

For the studied fit windows we also retrieved the $\mathrm{BrO}$ profile by the AMF modified DOAS. The agreement with the Taylor series approach is within $5 \%$ for altitudes between 15 and $25 \mathrm{~km}$, except for the fit window of 332.02-339.94 nm where only the first two $\mathrm{BrO}$ absorption peaks are considered in the fit. In this case the Taylor series approach gives $\sim 10 \%$ lower values for altitudes above the peak compared with AMF modified DOAS and the true profile.

\subsection{Application of the method for different atmospheric conditions}

In the previous section, the effect of the Taylor series approach for the wavelength dependency of the ozone SCDs in the DOAS fit was investigated for one predefined atmospheric condition with large absorption of ozone ( $\mathrm{VCD}=460 \mathrm{DU})$ and a $\mathrm{SZA}$ of $75^{\circ}$, according to the main settings in Table 1. In this section, the performance of the approach is investigated for different atmospheric conditions. 

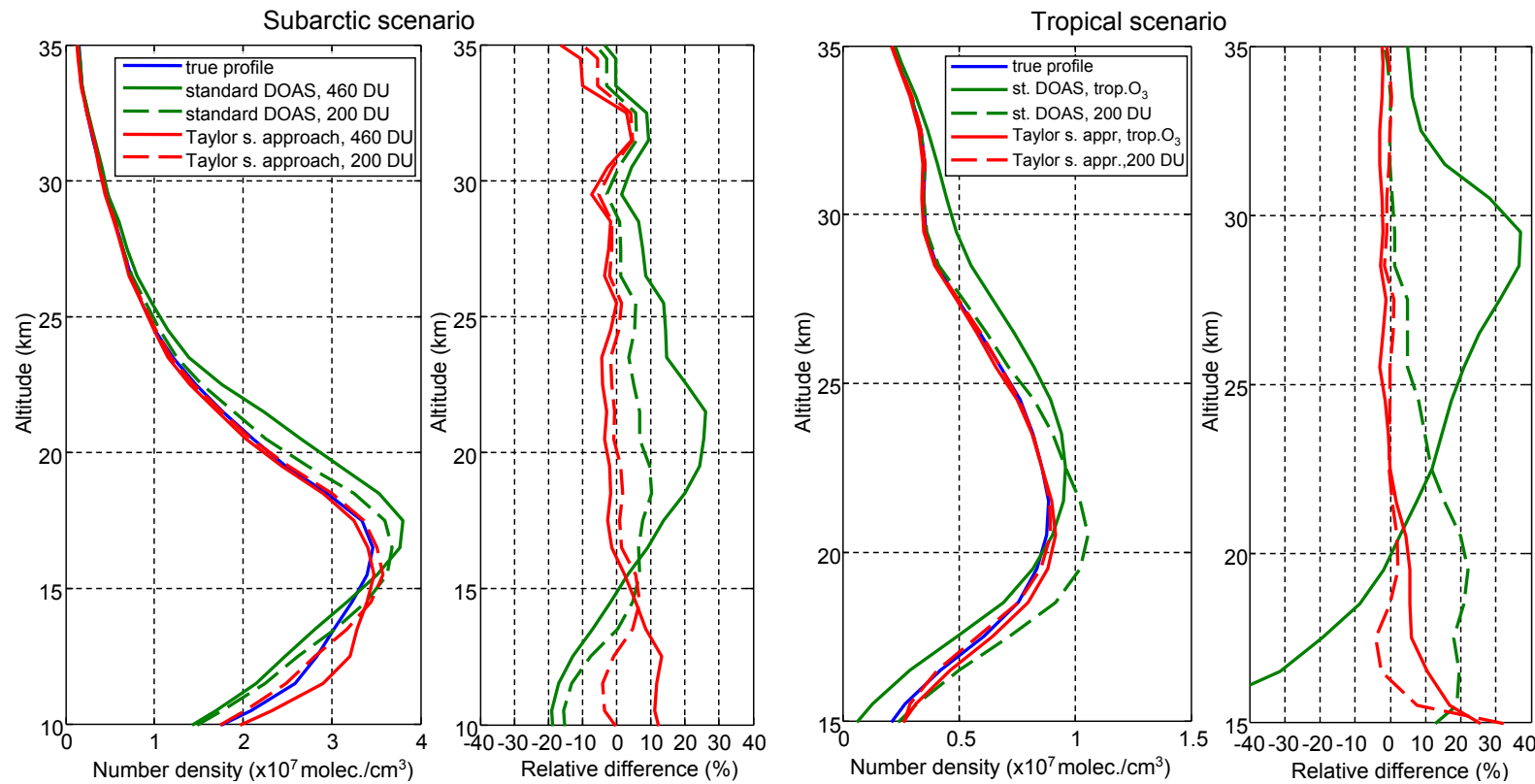

Fig. 8. Retrieved concentration profiles of BrO from simulated spectra by the standard DOAS and Taylor series approach (first and third panel from left) and the relative differences with the true profile (second and fourth panel). Left panels: Result for the subarctic atmospheric scenario where besides the simulation of spectra using the ozone profile with VCD $=460 \mathrm{DU}$ also a simulation for an ozone profile scaled to $\mathrm{VCD}=200 \mathrm{DU}$ is performed. Right panels: Result for a tropical scenario with a tropical ozone profile with the maximum at $28 \mathrm{~km}$ and also for a subarctic profile (scaled to $200 \mathrm{DU}$ ) with the peak at $19 \mathrm{~km}$.

The response of the approach to different ozone profiles is of particular interest. In case studies we found that other atmospheric parameters that impact the light distribution in the atmosphere (temperature, pressure, as well as viewing geometry) have a very small effect compared with the effect caused by ozone absorption.

In the following, we investigate: (1) the effect of different vertical optical depths of ozone on the retrieval of $\mathrm{BrO}$ by scaling the ozone profile, and (2) the effect of a different ozone profile with the concentration peak at higher altitudes. For the simulation of spectra we apply the ozone profiles shown in Fig. 2 and Table 1. In the first case, for the subarctic scenario, the ozone profile with $\mathrm{VCD}=460 \mathrm{DU}$ is scaled to $200 \mathrm{DU}$. In the second case, for tropical scenario, besides applying the ozone profile characteristic for the tropics $(\mathrm{VCD}=270 \mathrm{DU}$, the profile peak at higher altitude, i.e. at $28 \mathrm{~km}$ ), also the subarctic profile (with peak at $18 \mathrm{~km}$, scaled to $200 \mathrm{DU}$ ) is applied.

The retrieved $\mathrm{BrO}$ profiles and their relative difference with respect to the true profile are given in Fig. 8.

When the ozone profile is scaled down from $460 \mathrm{DU}$ to $200 \mathrm{DU}$, a better agreement for the retrieved profile of $\mathrm{BrO}$ with the true profile is obtained both for standard DOAS and for the Taylor series approach (see Fig. 8, left panel). For standard DOAS, at most altitudes the agreement is within 10\% (Fig. 8, second panel from left). For the Taylor series approach, the agreement is within $2 \%$ between 16 and $30 \mathrm{~km}$.
Like for standard DOAS, this improvement can be explained by the decreased contribution of the ozone optical depth to the total optical depth of absorption. Accordingly, the effects of uncorrected higher order Taylor series terms and the impact of minor absorbers on the absorption of ozone decrease relative to the total optical depth.

For the tropical scenario (Fig. 8, two panels on the right) even larger relative discrepancies (up to $40 \%$ ) for the profiles retrieved by standard DOAS (see the solid green line in the plot) can be seen than for the subarctic scenarios studied before. The larger relative discrepancy can be explained by the lower $\mathrm{BrO}$ concentration. The absolute discrepancy, however, is similar to the scenario with the subarctic profile of ozone scaled to $200 \mathrm{DU}$. The largest discrepancy is observed at higher altitudes (above $25 \mathrm{~km}$ ), compared with the subarctic scenario studied previously, because the ozone concentration peaks at higher altitudes $(28 \mathrm{~km})$ in the tropics (Fig. 2). This becomes clear from a study where the tropical ozone profile is replaced by the subarctic ozone profile scaled to $200 \mathrm{DU}$ which peaks at lower altitudes $(19 \mathrm{~km})$. For the latter, the largest disagreement of $20 \%$ is found at lower altitudes (below $20 \mathrm{~km}$ ), i.e., near the peak of the ozone profile (dashed green line in the far right plot of Fig. 8).

The absolute difference between the $\mathrm{BrO}$ profile, retrieved by the Taylor series approach, and the true profile is similar for the cases with the tropical and the subarctic profile (the latter scaled to VCD of $200 \mathrm{DU}$ ) because the ozone profile for 
the tropics has a similar VCD (270 DU). In relative values, the discrepancy for the tropical profile is lower than 5\% for altitudes above $20 \mathrm{~km}$, but increases for altitudes below.

\section{Application of the method to SCIAMACHY measurements}

In the previous two sections, we showed the advantage of the Taylor series approach for the retrieval of $\mathrm{BrO}$ vertical profiles from simulated spectra. In the following we study the possibility to apply the method for the retrieval of $\mathrm{BrO}$ vertical profiles from SCIAMACHY limb measurements. We perform the retrieval of SCDs by standard DOAS and by the Taylor series approach and compare the retrieved vertical concentration profiles with correlated balloon measurements provided by Dorf et al. $(2006,2008)$.

Note that in comparison to the simulation studies larger errors are expected for real measurements. These include effects of the temperature dependency of the cross-sections, the spectral calibration, the Ring effect and instrumental problems. For the comparison of measurements from different instruments, trajectory modelling and photochemical correction for balloon measurements contribute to additional uncertainties. Also note that for the balloon retrieval, a different BrO cross-section (Wahner et al., 1988) for the DOAS fit was used and the retrieval was performed in another fit window.

\subsection{Instrument description}

The SCIAMACHY instrument on the ENVISAT satellite operates in a near polar sun synchronous orbit with an inclination from the equatorial plane of $\sim 98.5^{\circ}$. It performs one orbit in approximately $100 \mathrm{~min}$ with equator crossing time of 10:00 in descending node. The satellite probes the atmosphere at the day side of Earth in alternating sequences of nadir and limb measurements. Limb scans in one scanning sequence are performed with approximately $3.3 \mathrm{~km}$ elevation steps at the TP in flight direction. The cross track swath is $960 \mathrm{~km}$ at the TP and consists of up to 4 pixels for the UV/VIS spectral range. The field of view (FOV) is $0.045^{\circ}$ in elevation and $1.8^{\circ}$ in azimuth. This corresponds to approximately $2.5 \mathrm{~km}$ in vertical direction and $110 \mathrm{~km}$ in horizontal direction at TP, respectively. SCIAMACHY measures in the UV-VIS-NIR spectral range from 240 to $2380 \mathrm{~nm}$ with a spectral resolution of approximately 0.25 to $0.55 \mathrm{~nm}$ in the UV-VIS range. More instrumental details can be found in Bovensmann et al. (1999).

\subsection{Retrieval of BrO}

For the retrieval of $\mathrm{BrO}$ vertical profiles from the SCIAMACHY limb measurements, an algorithm developed in our group is applied (Kühl, 2005; Puķīe et al., 2006; Kühl et al., 2008). The retrieval of vertical $\mathrm{BrO}$ profiles is performed in two steps in a similar way as for the simulated spectra studies above.

In the first step, the retrieval of SCDs, we apply the same retrieval settings as described in Kühl et al. (2008). The fit window ranges from $338.01-357.25 \mathrm{~nm}$ and two ozone cross-sections (at 223 and $243 \mathrm{~K}$ ) by Bogumil et al. (2003) are included in the fit in order to account for the temperature dependency of ozone cross-section. In the current study, the cross-section at $243 \mathrm{~K}$ is replaced with the one at $203 \mathrm{~K}$ for cases when temperature drops below $210 \mathrm{~K}$ in the lower stratosphere in order to apply the cross-sections best fitting to the actual temperature profile.

For the Taylor series approach we implement the description of wavelength and absorption dependency of the ozone SCD in the fit window in the same way as for the simulated spectra: compared to the standard DOAS approach the ozone cross-section term at $223 \mathrm{~K}$ is replaced by the three terms given in Eq. (14). The second cross-section term at $243 \mathrm{~K}$ (or $203 \mathrm{~K}$ ) is left unchanged as the purpose of it is to account for the dependency of the ozone cross-section on temperature. We simulated spectra accounting for the temperature dependency of the ozone cross-section and found that the spectral features of ozone absorption due to temperature are well accounted for with this one additional term. Expansion of it in the Taylor series does not give additional improvement. Also orthogonalization of the ozone cross-section of $243 \mathrm{~K}$ (or $203 \mathrm{~K}$ ) with respect to the cross-section of $223 \mathrm{~K}$ does not affect the retrieval.

For the second step of the retrieval, the inversion of the $\mathrm{BrO}$ SCDs to a number density profile of $\mathrm{BrO}$, we apply the RTM McArtim (Deutschmann, 2009), like for the simulations above. Box AMFs according to the geometry of each individual SCIAMACHY measurement are calculated at the single wavelength of $344.2 \mathrm{~nm}$ (as shown for example in Sect. 3.2.2, see dashed red line in Fig. 4). In case studies we found that for this wavelength the retrieved and the true SCDs agree within $\sim 3 \%$ for different ozone profiles (see e.g. Fig. C1, second panel from top, in the Appendix C). Thus with this practical solution it is not necessary to calculate the box AMFs at all wavelengths which would be a very time consuming task for every SCIAMACHY measurement. The inversion is performed by the optimal estimation method (Rodgers, 2000). It is performed on the measurement grid with an a priori uncertainty of $100 \%$ and the off-diagonal elements of the covariance matrix equal to zero.

\subsection{Comparison of SCIAMACHY BrO measurements with collocated balloon measurements}

A number of balloon measurements were performed to validate the SCIAMACHY instrument (e.g. Butz et al., 2006; Dorf et al., 2006). The BrO profiles taken for this study were acquired from direct solar spectra measurements by LPMA/DOAS (Dorf et al., 2006). A photochemical correction and air mass trajectory modelling was performed for the 
balloon measurements in order to match the same location and atmospheric conditions (i.e., SZA) as for SCIAMACHY. A time mismatch between the satellite observation and the air mass trajectory starting at the balloon observation smaller than $1 \mathrm{~h}$ and a distance mismatch smaller than $500 \mathrm{~km}$ were allowed. If no SCIAMACHY observations fulfill these criteria, the distance criterion was extended to $1000 \mathrm{~km}$. For the backward and forward trajectory modelling and for further information on the balloon measurements and the profile retrieval please refer to Dorf et al. (2006, 2008).

In Fig. 9, the BrO profiles retrieved by SCIAMACHY are compared with the correlated balloon observations performed for: Kiruna $\left(67.9^{\circ} \mathrm{N}, 21.1^{\circ} \mathrm{E}\right)$, Aire sur l'Adour $\left(43.7^{\circ} \mathrm{N}, 0.3^{\circ} \mathrm{E}\right)$ and Teresina $\left(5.1^{\circ} \mathrm{S}, 42.9^{\circ} \mathrm{W}\right)$ in March, October and June, respectively. The altitude range at which the modelled trajectories of air masses measured by balloon match with the TPs of the SCIAMACHY limb observations are indicated by gray shading in the figure.

It can be clearly observed that the profiles retrieved from the SCDs acquired by standard DOAS generally show larger values compared with the Taylor series approach (violet dashed line in Fig. 9, right hand side). The difference between both retrievals is about 10 to $25 \%$, in accordance with the findings for the studies on the simulated spectra (see Sect. 4.2).

Also, the dependence on the ozone VCD is very similar: The discrepancy is the largest for measurements at Kiruna, where it is up to $25 \%$ for altitudes between 20 and $25 \mathrm{~km}$. For this comparison, very large ozone VCD (above $400 \mathrm{DU}$ ) were observed above Kiruna in March. Therefore the large discrepancy between the profiles obtained by standard DOAS and the Taylor series approach at the altitudes of the ozone peak may be attributed to the impact of the ozone absorption, which causes the overestimation of the BrO SCD by standard DOAS (compare Fig. 8).

In contrast, for the observation above Aire sur l'Adour in October, the difference between both SCIAMACHY retrievals is smaller (between 10 and 15\%) because of the much smaller ozone VCD (below 300 DU) compared with Kiruna. Thus, the impact of ozone absorption on the $\mathrm{BrO}$ retrieval is less at this site and standard DOAS shows a good agreement with the balloon observations here.

For the tropical scenario over Brazil the standard DOAS gives $10-40 \%$ larger values compared with the Taylor series approach. The discrepancy is larger for altitudes above $25 \mathrm{~km}$ which is again in very good accord with the sensitivity studies for the tropical scenario (see Sect. 4.2).

In spite of the difficulties to be expected when comparing remote sensing observations of the minor absorbing species from different platforms, for most altitudes where the air masses measured by balloon and SCIAMACHY match, a good agreement within error bars is found for the Taylor series approach. For wide altitude ranges, the discrepancy is within $25 \%$, for certain altitudes also below $10 \%$ and always within $40 \%$ for both Kiruna cases (first and third panel from the top) and 10\% at Aire sur 1'Adour in France (second panel from the top). In contrast, the discrepancy of the standard DOAS retrieval to the balloon profiles is significantly higher (around $\sim 50 \%$ for Kiruna).

For the tropical case (bottom panel), significantly lower values are observed by up to $35 \%$ compared with the balloon observation for altitudes below $25 \mathrm{~km}$ although showing good agreement above. Currently we cannot provide an explanation for this discrepancy, except that there are still large uncertainties regarding the observations of stratospheric BrO. In particular, only very few measurements have been performed so far for the tropical lower stratosphere (Dorf et al., 2008). However for this case, also other SCIAMACHY retrieval algorithms retrieve lower concentrations from the SCIAMACHY measurements (A. Rozanov, personal communication, 2009). Note that for all compared $\mathrm{BrO}$ profile retrievals the agreement with the profiles obtained by the IUP Bremen full retrieval approach (Rozanov et al., 2005) is improved when applying the Taylor series approach compared to standard DOAS (compare with results presented in Sheode et al., 2006). The improved agreement is expected, because the full retrieval approach by itself correctly considers the wavelength dependence of the SCDs. A comparison of $\mathrm{BrO}$ profiles retrieved from SCIAMACHY measurements by algorithms of different retrieval groups with each other and with balloon validation measurements will be presented in a publication by Rozanov et al. (2010).

\section{Conclusions}

For complex measurement geometries like in satellite limb measurements, light propagation in the atmosphere strongly varies with wavelength. The light can reach the instrument along very different light paths including those with strong absorption (e.g. due to ozone in the UV/VIS spectral range). In such cases DOAS is not directly applicable without accounting for the changes in the light propagation with wavelength because the assumption of a constant SCD within the DOAS fit window will lead to significant systematic errors.

For such cases, modifications of DOAS can be introduced that account for the variability of the SCD within the fit window (e.g., extended or AMF modified DOAS). We introduced a new approach that describes the SCD as function of wavelength and of vertical optical depth by accounting for the broad band variation with wavelength due to changes in light propagation and absorption, and by considering the narrow band dependency of absorption varying with crosssection. The functional relationships are expressed in a Taylor series of which the first order terms are included in the DOAS fit, allowing to account for the wavelength dependency of the SCD. Thus, wavelength dependent SCDs are determined by DOAS.

Applying the Taylor series approach to SCIAMACHY limb observations, more correct $\mathrm{BrO}$ profiles can be retrieved 


\section{Vertical BrO profile}

\section{Relative difference}

23 March 2003, Kiruna $\left(67.9^{\circ} \mathrm{N}, 21.1^{\circ} \mathrm{E}\right)$ Backward match: Orbit 5545, at $75^{\circ} \mathrm{N}, 16^{\circ} \mathrm{E}$
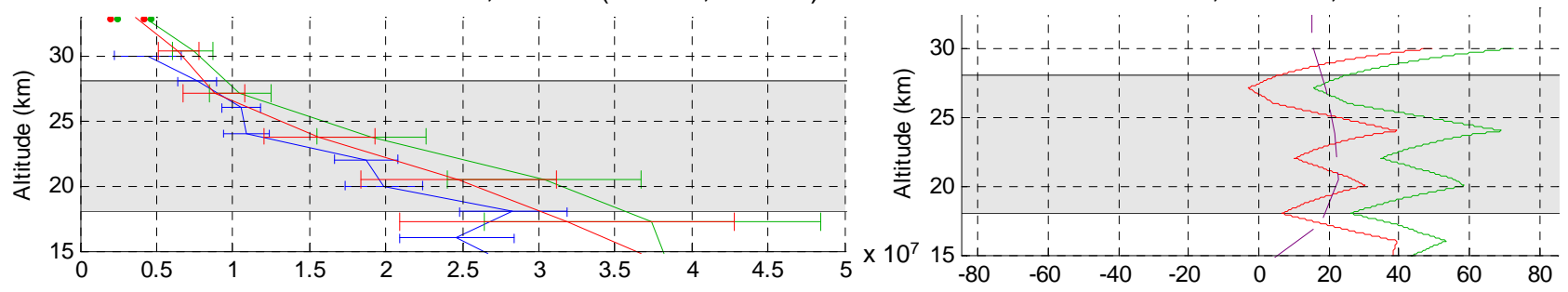

9 Oct 2003 , Air sur l'Adour $\left(43.7^{\circ} \mathrm{N}, 0.3^{\circ} \mathrm{E}\right)$ Backward match: Orbit 8407 , at $41^{\circ} \mathrm{N}, 8^{\circ} \mathrm{E}$
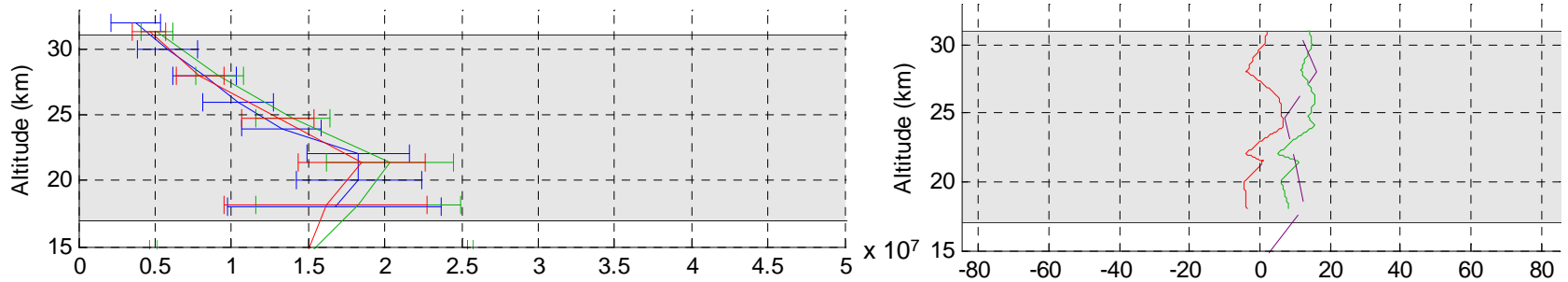

24 March 2004, Kiruna $\left(67.9^{\circ} \mathrm{N}, 21.1^{\circ} \mathrm{E}\right)$ Backward match: Orbit 10798 , at $66^{\circ} \mathrm{N}, 9^{\circ} \mathrm{E}$
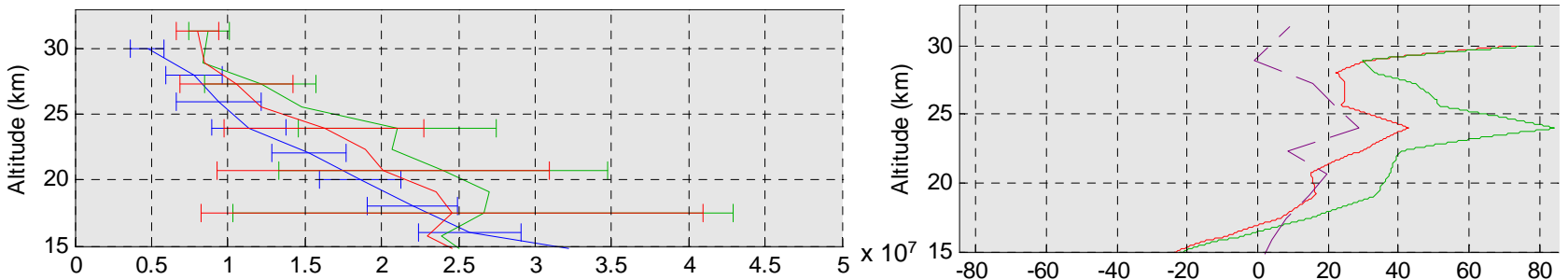

27 June 2005 , Teresina $\left(5.1^{\circ} \mathrm{S}, 42.9^{\circ} \mathrm{W}\right)$ Forward match: Orbit 17255 , at $5^{\circ} \mathrm{S}, 48^{\circ} \mathrm{W}$
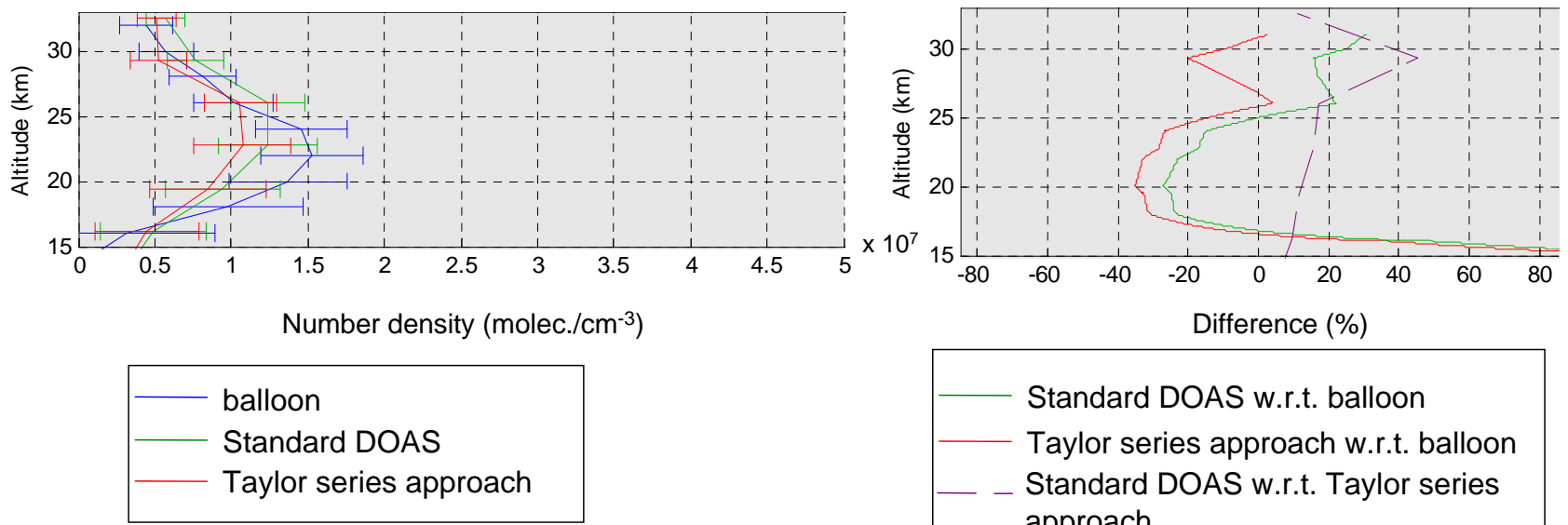

balloon

Standard DOAS

Taylor series approach

Standard DOAS w.r.t. balloon

Taylor series approach w.r.t. balloon

Standard DOAS w.r.t. Taylor series approach

Fig. 9. Comparison of BrO profiles derived from balloon observations (Dorf et al., 2006, 2008) with SCIAMACHY limb retrievals for four different balloon launches as indicated on the titles of the panels. Shown is the comparison either for the backward or the forward match of the trajectory modelling. The match for the largest altitude range with correlated data is chosen. The altitude range where the sounded air masses match is indicated by a gray shading. On the left panel the blue lines represent the balloon profiles photochemically corrected to match the SZA of the SCIAMACHY measurement. The SCIAMACHY measurements are shown as red lines for the Taylor series approach and as green lines for the standard DOAS. On the right panel the relative differences between the SCIAMACHY and balloon profiles (green and red lines) and between the different approaches of SCIAMACHY (violet dashed line) are shown. 
(compared with the standard DOAS approach). At the same time, the advantages of a two step approach are retained: radiative transfer is separated from spectral analysis, saving calculation time for both steps. In particular, box AMFs can be calculated at one selected single wavelength.

Studies based on simulated spectra demonstrated the usefulness of the method for different spectral regions in the range of $332-357 \mathrm{~nm}$. In this region, relatively strong absorption by ozone prevails and the light path distribution in the atmosphere changes considerably with wavelength. Here, neglecting the dependency of ozone SCDs on wavelength leads to significant cross-effects for the retrieval of minor absorbers like BrO: Depending on the fit window the discrepancy to the true profile can reach 20 to $100 \%$.

Accounting for this variation by the Taylor series approach provides a more correct retrieval of minor absorbers and eliminates biases that arise due to the assumption of the constant ozone SCD in the fit window: Sensitivity studies show that the agreement between the retrieved and simulated BrO SCDs is very good for atmospheric scenarios with different ozone profiles. Consequently, also for the retrieved and true $\mathrm{BrO}$ profile a very good accord is found for different fit windows and ozone profiles.

We applied the Taylor series approach to the retrieval of $\mathrm{BrO}$ profiles from SCIAMACHY measurements and compared the results with those from standard DOAS retrieval and correlated balloon measurements. While profiles obtained by standard DOAS show discrepancies of up to $\sim 50 \%$ compared to the balloon validation measurements, the Taylor series approach leads to much better agreement, in particular for cases with strong ozone absorption. This confirms the results of the sensitivity studies where an overestimation of the BrO SCD due to an incorrect ozone SCD description by standard DOAS was found.

Compared to AMF modified DOAS, the Taylor series approach has the advantage of being independent from a priori information that may, in general, differ from reality. In addition, it is not necessary to calculate AMFs for every wavelength in the fit window.

For the inversion of SCDs to vertical profiles, the new approach makes the RTM calculations much easier because the interference of the narrow band spectral features caused by the wavelength dependency of the SCD of strong absorbers with minor absorber is minimized. Therefore, the selection of the wavelength at which the box AMFs for the inversion should be calculated depends much less on the strength of the absorption by ozone.

We demonstrated the improvement for the $\mathrm{BrO}$ profile retrieval by the Taylor series expansion applied for SCDs of ozone for simulated and measured spectra. In simulation studies we also showed the possibility to extend this approach for a minor absorber (i.e., BrO). However, the approach has the potential to improve DOAS retrievals also for other minor or strong absorbers when strong absorption is present in the atmosphere, and is not limited to limb geometry. In general, the approach allows to extend the applicability of DOAS for observations where the light path varies strongly with wavelength (e.g., limb measurements or scenarios with large SZAs for nadir, ground based or other observations), or where medium or strong absorptions occur (e.g., ozone in the UV spectral range). Moreover, due to the improved description of the wavelength dependency of the SCDs, the Taylor series approach also allows to use broader fit windows which could improve the extraction of signals of very weak absorbers.

\section{Appendix A}

\section{Approximation for the spectral variation of simulated AMFs of ozone in the UV spectral range for limb geometry}

In this appendix we investigate how well the approximation of ozone AMFs by the Taylor series approach agrees with its true function of wavelength. Because of the proportionality between AMF and SCD in Eq. (3), similar conclusions for the SCDs can be drawn.

For the study, we simulated AMFs for limb geometry in the UV spectral region (338-357 nm), see "main" parameters given in Table 1. The AMFs are obtained by the RTM McArtim (Deutschmann, 2009) from the simulated spectral intensity with and without the ozone absorption (according to the second bottom row in the third column in Table 3 ).

In analogy to Eq. (6), taking into account the proportionality between AMF and SCD, the first order approximation for AMFs is described by:

$A(\lambda, v) \approx A_{0}^{*}+A_{\lambda} \lambda+A_{v} v$

In the simulated wavelength region, although minor absorbers are present, absorption by ozone dominates. Therefore, for the determination of the vertical optical depth $v$ we first neglect the impact of minor absorbers by considering only the absorption of ozone $\left(v_{O_{3}}=V_{O_{3}} \sigma_{O_{3}}\right)$ in analogy to Eq. (9):

$A(\lambda, v) \approx A_{0}^{*}+A_{\lambda} \lambda+A_{\mathrm{O}_{3}} \sigma_{\mathrm{O}_{3}}$

Note that $A_{O_{3}}$ is a product of $A_{v}$ and the ozone VCD. The coefficients $A_{0}^{*}, A_{\lambda}$ and $A_{\mathrm{O}_{3}}$ are acquired by minimizing the difference between the right side of Eq. (A2) and the simulated (true) AMF on the left side. In Fig. A1, the difference between the approximation by the Taylor series and the true values is plotted as mean for all THs (case a, blue line) in order to show the general effect. The agreement is better than $\sim 0.4 \%$ for all wavelengths (the discrepancy is slightly larger for THs close to the peak of the BrO profile and lower above).

This means that with respect to the simplification of a constant AMF, where discrepancies of up to $20 \%$ arise for certain wavelengths (compare Fig. 1), the new approach has a maximum discrepancy of only $0.4 \%$ for the whole fit window. 
Table A1. Terms of Taylor series expansion considered in the AMF fit study.

\begin{tabular}{|c|c|c|c|}
\hline & \multicolumn{3}{|c|}{ Taylor series terms considered in the fit } \\
\hline Cases & Constant term & Linear terms & Square terms \\
\hline Case a & $A_{0}$ & $A_{\lambda \lambda}, A_{\mathrm{O}_{3}} \sigma_{\mathrm{O}_{3}}$ & - \\
\hline Case $b$ & $A_{0}$ & $A_{\lambda \lambda}, A_{\mathrm{O}_{3}} \sigma_{\mathrm{O}_{3}}, A_{\mathrm{BrO}} \sigma_{\mathrm{BrO}}$ & - \\
\hline Case $\mathrm{c}$ & $A_{0}$ & $A_{\lambda \lambda}, A_{\mathrm{O}_{3}} \sigma_{\mathrm{O}_{3}}, A_{\mathrm{BrO}} \sigma_{\mathrm{BrO}}, A_{\mathrm{NO}_{2}} \sigma_{\mathrm{NO}_{2}}$ & - \\
\hline Case $\mathrm{d}$ & $A_{0}$ & $A_{\lambda \lambda}, A_{\mathrm{O}_{3}} \sigma_{\mathrm{O}_{3}}, A_{\mathrm{BrO}} \sigma_{\mathrm{BrO}}, A_{\mathrm{NO}_{2}} \sigma_{\mathrm{NO}_{2}}$ & $A_{\lambda \lambda} \lambda^{2}, A_{\lambda_{\mathrm{O}_{3}}} \lambda \sigma_{\mathrm{O}_{3}}, A_{\mathrm{O}_{3 \mathrm{O}_{3}}} \sigma_{\mathrm{O}_{3}}^{2}$ \\
\hline
\end{tabular}

The small differences that remain (for example, at 338.5 and $355 \mathrm{~nm}$ ) are due to the absorption bands of minor absorbers, which are included in the atmospheric scenario used for the simulation studies $\left(\mathrm{BrO}\right.$ and $\left.\mathrm{NO}_{2}\right)$, and also higher order structures with respect to wavelength and ozone absorption. They are not considered in the approximation by Eq. (A2) due to the small effect on the total vertical optical depth and consequently on the AMFs of ozone.

However, by considering the absorption of $\mathrm{BrO}$ in the vertical optical depth in the last term of Eq. (A1), i.e. including in the fit also the first order parameter $A_{\mathrm{BrO}} \sigma_{\mathrm{BrO}}$ (with $A_{\mathrm{BrO}}$, a product of $A_{v}$ and $\mathrm{BrO} \mathrm{VCD}$ ) as an additional term in Eq. (A2), an improvement by an additional order of magnitude at the strongest absorption band of $\mathrm{BrO}$ is achieved (case b, green line in Fig. A1). Table A1 lists the terms included for the different approximation cases.

Furthermore, it is also possible to correct for the still remaining systematic effects by including also the term $A_{\mathrm{NO}_{2}}$ for $\mathrm{NO}_{2}$ (case c, cyan line in the Fig. A1). An agreement close to the precision of the simulation noise is obtained when additionally including the parameters for the second order terms for the dependency on wavelength and absorption of ozone $\left(A_{\lambda \lambda}, A_{\lambda \mathrm{O}_{3}}\right.$ and $\left.A_{\mathrm{O}_{3} \mathrm{O}_{3}}\right)$, see case d, red line.

From this level of agreement one may deduce that this Taylor series expansion does not neglect (in the extent of practical applicability) any systematic effects on the wavelength dependency of the AMF. On the other hand, already the first order Taylor series approach significantly improves the description of the wavelength dependency of the AMF.

\section{Appendix B}

\section{Sensitivity to different terms of the Taylor series}

In the following, we investigate the quality of the retrieval when accounting for either only the broad band (due to scattering and absorption) or narrow band (due to ozone absorption) variation of SCDs of ozone in the fit window.

First, we include in the comparison the results when only the broad band dependency of the ozone SCD on wavelength is considered in the DOAS fit, but the term describing the dependency on the ozone cross-section is neglected, Eq. (14)

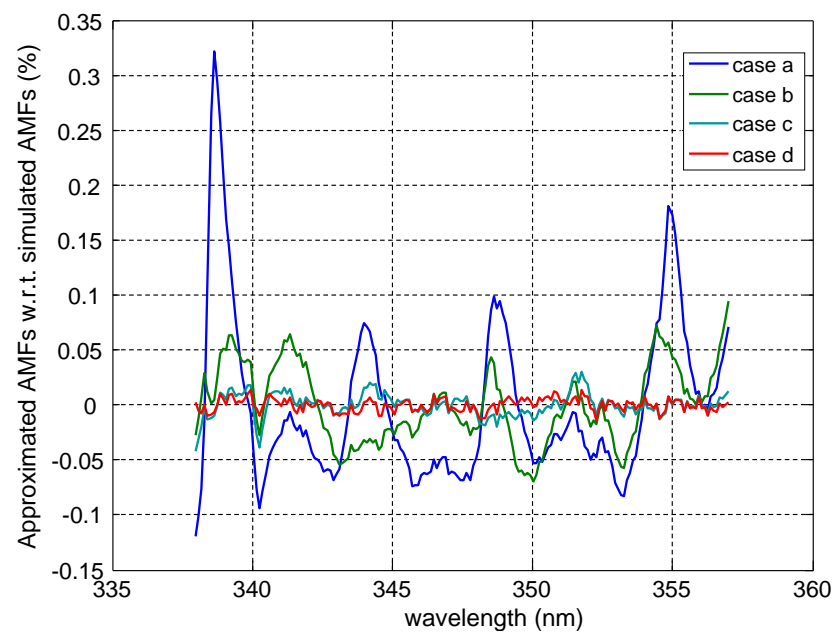

Fig. A1. Relative difference between AMFs of ozone approximated by Taylor series and simulated AMFs for the main settings (see Table 1). Different lines correspond to results obtained by considering different number of Taylor series terms as fit parameters as listed in Table A1. The difference is averaged for all tangent heights. Compare with Fig. 1 to see the improvement with respect to a constant AMF.

then becomes:

$\ln \frac{I_{0}}{I}=S_{0, \mathrm{O}_{3}}^{*} \sigma_{\mathrm{O}_{3}}+S_{\lambda, \mathrm{O}_{3}} \lambda \sigma_{\mathrm{O}_{3}}$
$+S_{\mathrm{NO}_{2}} \sigma_{\mathrm{NO}_{2}}+S_{\mathrm{BrO}} \sigma_{\mathrm{BrO}}+P$

In this case, the wavelength dependent SCD of ozone can be calculated from the fitted parameters in the following way:

$S_{f}=S_{0, \mathrm{O}_{3}}^{*}+S_{\lambda, \mathrm{O}_{3}} \lambda$

Alternatively, the wavelength dependency of the SCD of ozone is considered only with respect to the spectral features of ozone absorption, neglecting the term describing the broad band dependency on wavelength. Equation (14) reduces to:

$\ln \frac{I_{0}}{I}=S_{0, \mathrm{O}_{3}}^{*} \sigma_{\mathrm{O}_{3}}+S_{\mathrm{O}_{3}, \mathrm{O}_{3}} \sigma_{\mathrm{O}_{3}}^{2}$
$+S_{\mathrm{NO}_{2}} \sigma_{\mathrm{NO}_{2}}+S_{\mathrm{BrO}} \sigma_{\mathrm{BrO}}+P$ 


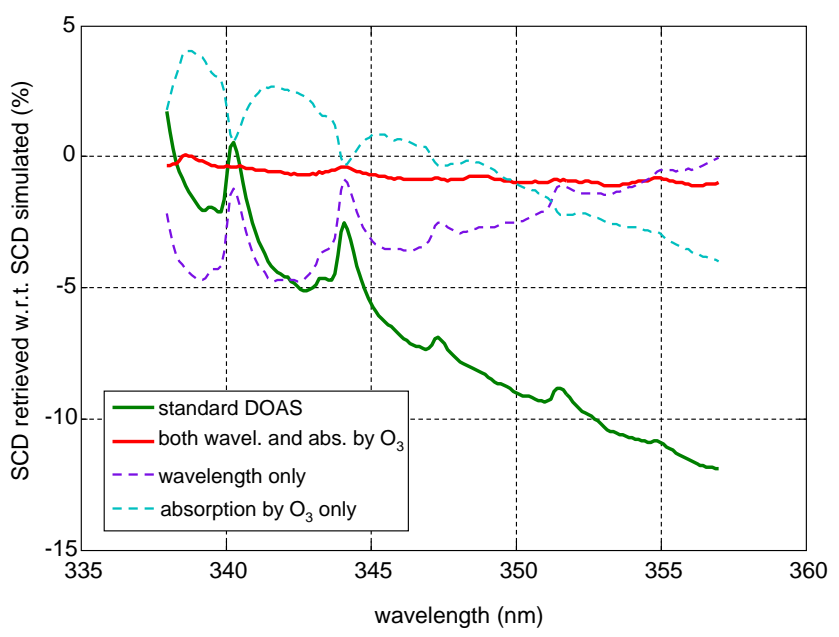

Fig. B1. Relative difference between the retrieved SCDs and the true (simulated) SCDs of ozone at $\mathrm{TH}=19.8 \mathrm{~km}$ if different terms describing the variation of SCD of ozone in the fit window are considered.

In this case, the wavelength dependent SCD of ozone is expressed by:

$S_{f}=S_{0, \mathrm{O}_{3}}^{*}+S_{\mathrm{O}_{3}, \mathrm{O}_{3}} \sigma_{\mathrm{O}_{3}}$

We compare the ozone SCDs retrieved by the different approaches with the true SCDs. Figure B1 shows the deviation of the retrieved SCDs from the simulated values. For this study, the same atmospheric and trace gas profiles as in the previous section (the main settings in Table 1), and the same fit window of 338-357 $\mathrm{nm}$ are applied.

Besides the observed error of up to $12 \%$ by the standard DOAS (the green line in the figure) and the improvement by one order of magnitude for the Taylor series approach (the red line in the figure), significant uncorrected ozone structures are observed in the fit also for both approaches studied here. For the case when the ozone cross-section term is skipped, but the wavelength variation is accounted for, negative deviations of up to $\sim 5 \%$ occur, which are stronger for THs near the ozone peak (dashed blue line in Fig. B1). The agreement improves for larger wavelengths outside the strong absorption structures of ozone. For the second case (dashed cyan line) where the wavelength term is skipped, an error in the range of 5 to $-5 \%$ is observed with better agreement at the absorption peaks of ozone. However, strong variations with wavelength in the fit window remain, thus it is only poorly improved with respect to the standard DOAS. Also, unfitted spectral structures of the ozone SCD remain in the fit residual.

Our studies show that neglecting one of the first order correction terms for ozone (broad band or ozone absorption) leads to poor results for the retrieval of the ozone SCD. However, for the retrieval of the $\mathrm{BrO}$ profile, there are only slight deviations found for the selected wavelength range of $338-357 \mathrm{~nm}$ and the studied atmospheric scenario (see Sect. 4.1 and second panel from top, left plot in Fig. 7).

\section{Appendix C \\ Comparison between retrieved and true BrO SCDs for different DOAS fits}

Herein the retrieved SCDs of $\mathrm{BrO}$ are compared with the simulated SCDs for the fit window $338-357 \mathrm{~nm}$. The comparison is performed for standard DOAS, the Taylor series approach applied to the SCD of ozone, and the AMF modified DOAS for the SCD of ozone. Additionally the Taylor series approach is implemented for the SCD of BrO. Thus, four different approaches for the BrO DOAS fit are investigated. Details are given in Table $\mathrm{C} 1$, where the fit arguments for the SCDs of ozone and $\mathrm{BrO}$ and the equations for the calculation of the $\mathrm{BrO}$ SCDs are given. Fig. $\mathrm{C} 1$ shows the differences between the retrieved SCDs of $\mathrm{BrO}$ and the simulated SCDs as a function of TH and wavelength for two different ozone profiles: the subarctic scenario with (a) the $\mathrm{VCD}=460 \mathrm{DU}$ and (b) the $\mathrm{VCD}=200 \mathrm{DU}$.

The possibility to apply box AMFs calculated at different single wavelengths for the inversion of the BrO SCDs to vertical profiles is also investigated. Figure $\mathrm{C} 2$ shows the relative differences between the retrieved $\mathrm{BrO}$ profiles and the true profile as a function of the wavelength used for the calculation of the box AMFs.

For standard DOAS (case a in Table $\mathrm{C} 1$ and upper panel in Figs. $\mathrm{C} 1$ and $\mathrm{C} 2$ ) a constant $\mathrm{BrO}$ SCD per TH is retrieved for the whole fit window. Thus, the variation with wavelength in the difference plot (Fig. C1, upper panel) arises because the true SCDs are wavelength dependent. It can be seen that the discrepancy between the retrieved and the simulated BrO SCD increases for THs where the absorption by ozone is larger (i.e. close to the altitude of the ozone profile peak, compare Fig. 2). Also, this discrepancy depends on the total ozone column: For the case with the ozone $\mathrm{VCD}=460 \mathrm{DU}$, the discrepancy is $20 \%$ at $19 \mathrm{~km}$ and $340.25 \mathrm{~nm}$, and for the case with the ozone VCD=200 DU, it is $8 \%$.

Box AMFs should be calculated at a wavelength where the retrieved SCD matches the true SCD. However, due to the strong variation with absorption of ozone and $\mathrm{TH}$ it is impossible to select one particular wavelength with the best match that is valid for all ozone profiles (not known a priori) and THs. This can be seen in Fig. C2 (top panel) where, for the scenario with the ozone VCD of $200 \mathrm{DU}$, the best agreement is at $345 \mathrm{~nm}$. At the same time, for the scenario with the ozone $\mathrm{VCD}=460 \mathrm{DU}$ this wavelength gives a disagreement of up to $15 \%$.

For the Taylor series approach, accounting for the variation of the ozone SCDs within the fit window (case b in Table $\mathrm{C} 1$ ), the fit improves significantly. The fit residual is reduced (compare with Fig. 5) and it is found that the retrieved 
Table C1. Fit terms describing the trace gas absorptions for different approaches in the DOAS fit and equations for the estimation of the BrO SCD from the fitted coefficients.

\begin{tabular}{|c|c|c|c|c|}
\hline Cases, short description & Ozone & $\mathrm{NO}_{2}$ & $\mathrm{BrO}$ & $\begin{array}{l}\text { Estimation for the } \\
\text { SCD of } \mathrm{BrO}\end{array}$ \\
\hline Case a (Standard DOAS) & $S_{\mathrm{O}_{3}} \sigma_{\mathrm{O}_{3}}$ & $S_{\mathrm{NO}_{2}} \sigma_{\mathrm{NO}_{2}}$ & $S_{\mathrm{BrO}} \sigma_{\mathrm{BrO}}$ & $S_{\mathrm{BrO}}$ \\
\hline $\begin{array}{l}\text { Case b (Taylor series approach for ozone } \\
\text { SCD) }\end{array}$ & $\begin{array}{l}S_{0, \mathrm{O}_{3}} \sigma_{\mathrm{O}_{3}} \\
S_{\lambda, \mathrm{O}_{3}} \lambda \sigma_{\mathrm{O}_{3}} \\
S_{\mathrm{O}_{3}, \mathrm{O}_{3}} \sigma_{\mathrm{O}_{3}}^{2}\end{array}$ & $S_{\mathrm{NO}_{2}} \sigma_{\mathrm{NO}_{2}}$ & $S_{\mathrm{BrO}} \sigma_{\mathrm{BrO}}$ & $S_{\mathrm{BrO}}$ \\
\hline $\begin{array}{l}\text { Case c (AMF modified DOAS for ozone } \\
\text { SCD) }\end{array}$ & $V_{\mathrm{O}_{3}} A_{\mathrm{O}_{3}} \sigma_{\mathrm{O}_{3}}$ & $S_{\mathrm{NO}_{2}} \sigma_{\mathrm{NO}_{2}}$ & $S_{\mathrm{BrO}} \sigma_{\mathrm{BrO}}$ & $S_{\mathrm{BrO}}$ \\
\hline $\begin{array}{l}\text { Case } d \text { (additionally the broad band vari- } \\
\text { ation with wavelength of the BrO SCD is } \\
\text { considered) }\end{array}$ & $\begin{array}{l}S_{0, \mathrm{O}_{3}} \sigma_{\mathrm{O}_{3}} \\
S_{\lambda, \mathrm{O}_{3}} \lambda \sigma_{\mathrm{O}_{3}} \\
S_{\mathrm{O}_{3}, \mathrm{O}_{3}} \sigma_{\mathrm{O}_{3}}^{2}\end{array}$ & $S_{\mathrm{NO}_{2}} \sigma_{\mathrm{NO}_{2}}$ & $\begin{array}{l}S_{0, \mathrm{BrO}} \sigma_{\mathrm{BrO}} \\
S_{\lambda, \mathrm{BrO}} \lambda \sigma_{\mathrm{BrO}}\end{array}$ & $S_{0, \mathrm{BrO}}+S_{\lambda, \mathrm{BrO}} \lambda$ \\
\hline
\end{tabular}

Case a, standard DOAS

Case b, Taylor s. a. for SCDs of ozone

Case c, AMF modified DOAS for SCDs of ozone

Case d, Taylor s. a. also with wavelength term for SCDs of $\mathrm{BrO}$
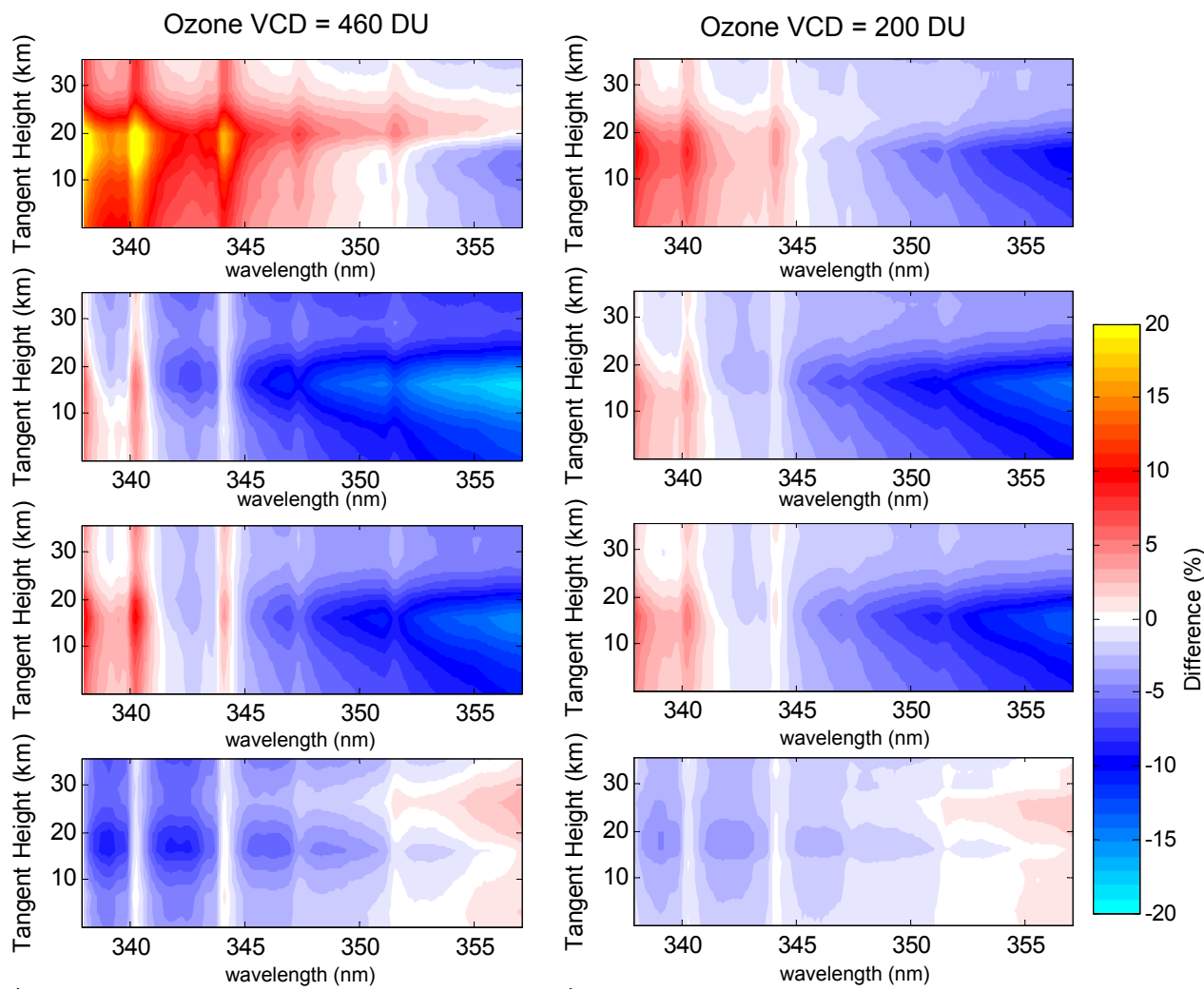

Fig. C1. Relative difference between retrieved SCDs of BrO and the true (simulated) SCDs as function of TH and wavelength for the studied cases (a)-(d) (see Table C1). The retrievals were performed for two different ozone profiles (with VCD=460 DU, on the left, and 200 DU, on the right, see Fig. 2.)

BrO SCD (fitted as wavelength independent like in standard DOAS) agrees better with the true wavelength dependent $\mathrm{BrO}$ SCDs, in particular at wavelengths where the strongest variation of its absorption cross-section occurs (see second panel from top in Fig. C1). For both scenarios of ozone absorption, the best agreement is found for the wavelength of
$344.2 \mathrm{~nm}$. Further case studies with a tropical atmospheric scenario show a similar agreement (not shown in the figure). Using box AMFs calculated at this wavelength for the profile retrieval results in a discrepancy between the retrieved and the true profile of less than 3\% (see Fig. C2, second panel from top). 
Case a, standard DOAS
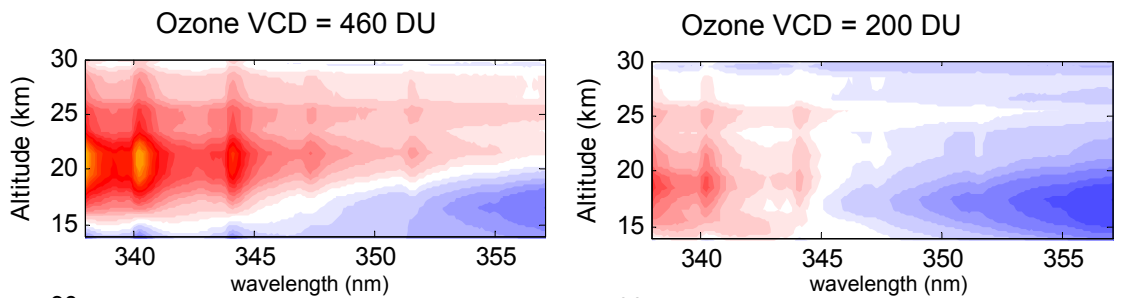

Case b, Taylor s. a. for SCDs of ozone
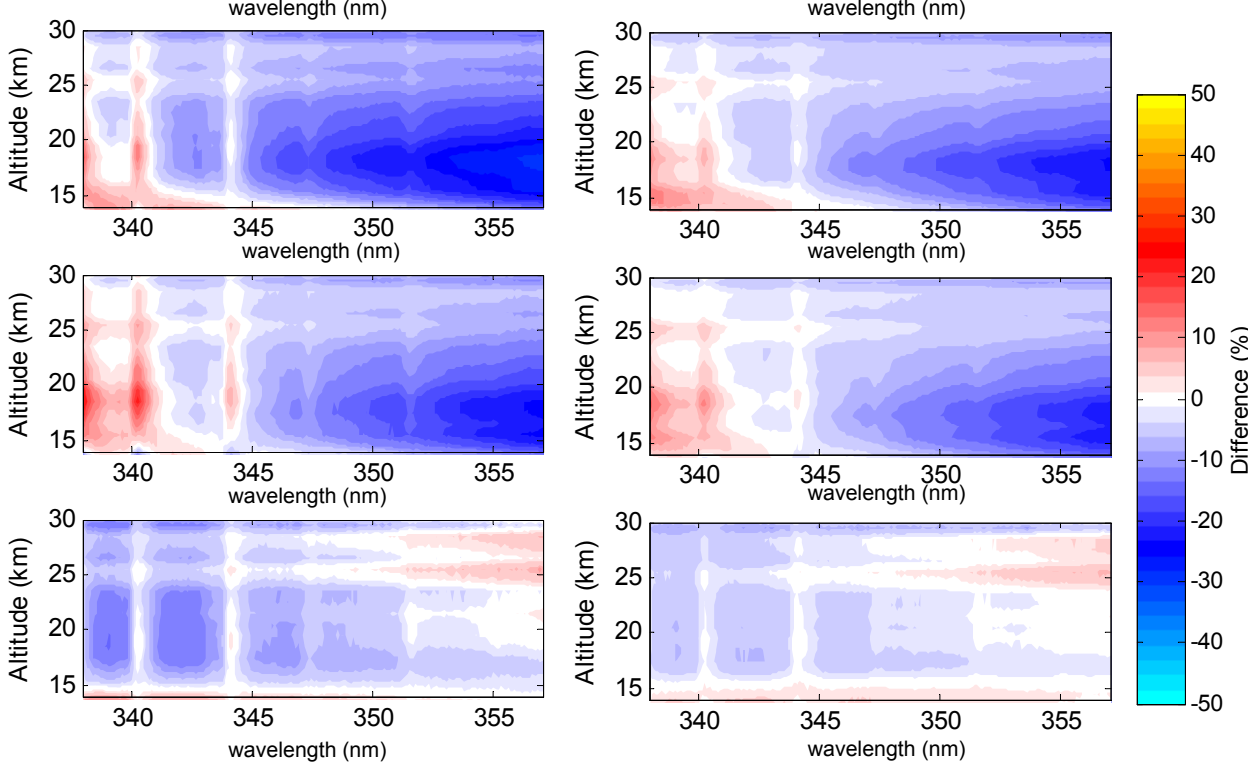

Case c, AMF modified DOAS for SCDs of ozone

Case d, Taylor s. a. also with wavelength term for SCDs of $\mathrm{BrO}$
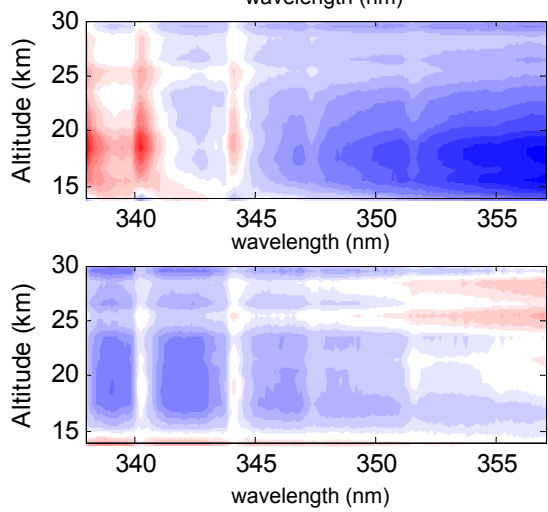

Fig. C2. Same as for Fig. C1 but relative differences between retrieved profiles applying box AMFs calculated at different wavelengths (x-axis) and the true vertical profile of $\mathrm{BrO}$ are shown.

For the AMF modified DOAS (case $\mathrm{c}$ in Table $\mathrm{C} 1$; Figs. $\mathrm{C} 1$ and $\mathrm{C} 2$ ) very similar results as for case $\mathrm{b}$ can be seen: also here the wavelengths where the fitted BrO SCD agrees with the simulated SCDs vary negligibly with TH and ozone profile.

Beside performing the Taylor series approach for the ozone SCDs, also the description of the optical depth of $\mathrm{BrO}$ in the DOAS fit may be improved by including also the first order Taylor series term for the SCD of $\mathrm{BrO}$ with respect to wavelength. For case $\mathrm{d}$ in Table $\mathrm{C} 1$ this term $\left(S_{\lambda, \mathrm{BrO}} \lambda \sigma_{\mathrm{BrO}}\right)$ is included in the DOAS equation in addition to the Taylor series approach for the ozone SCDs (compare Eq. 14).

Thus, the SCDs of $\mathrm{BrO}$ are retrieved as a linear function of wavelength. Since the fit is now constrained with two fit arguments for the BrO SCD, a much better agreement between the retrieved and simulated BrO SCDs is achieved (see bottom panel in Fig. C1). The discrepancy is less than 3\%, not only close to the wavelengths where the more rapid changes in the $\mathrm{BrO}$ absorption occur, but also for longer wavelengths (e.g., around $351.5 \mathrm{~nm}$ ). In comparison to case $\mathrm{b}$ the wavelengths, where the best agreement is found, vary even less with TH and ozone profile, simplifying the selection of an appropriate wavelength for the calculation of the box AMFs. Also, the agreement at longer wavelengths provides an advantage for the calculation of box AMFs for the inversion, because box AMFs at a longer wavelength are less influenced by ozone absorption, which is generally not known a priori. Figure $\mathrm{C} 2$, bottom panel shows that a good agreement (discrepancies smaller than 3\%) between the retrieved and true profile is achieved using box AMFs for inversion of BrO SCDs not only at $344.2 \mathrm{~nm}$, as for the case b, but also around $351.5 \mathrm{~nm}$.

Acknowledgements. We want to thank ESA and DLR for providing the SCIAMACHY level 1 data, and Marcel Dorf for providing the results of the balloon measurements, and Alexei Rozanov for fruitful discussions regarding the BrO profile retrieval, and Andreas Richter for comments on the AMF modified DOAS. One author (S. Kühl) is funded by the DFG (Deutsche Forschungs Gemeinschaft). We thank Marloes Penning de Vries (MPI for Chemistry, Mainz) for proofreading of the manuscript.

The service charges for this open access publication have been covered by the Max Planck Society.

Edited by: M. Weber 


\section{References}

Bogumil, K., Orphal, J., Homann, T., Voigt, S., Spietz, P., Fleischmann, O. C., Vogel, A., Hartmann, M., Bovensmann, H., Frerik, J., and Burrows, J. P.: Measurements of molecular absorption spectra with the SCIAMACHY pre-flight model: instrument characterization and reference data for atmospheric remotesensing in the 230-2380 $\mathrm{nm}$ region, J. Photoch. Photobio. A, 157, 167-184, 2003.

Bovensmann, H., Burrows, J. P., Buchwitz, M., Frerick, J., Noël, S., Rozanov, V. V., Chance, K. V., and Goede, A. P. H.: SCIAMACHY: Mission objectives and measurement modes, J. Atmos. Sci., 56, 127-150, 1999.

Buchwitz, M., Rozanov, V. V., and Burrows, J. P.: A near-infrared optimized DOAS method for the fast global retrieval of atmospheric $\mathrm{CH}_{4}, \mathrm{CO}, \mathrm{CO}_{2}, \mathrm{H}_{2} \mathrm{O}$, and $\mathrm{N}_{2} \mathrm{O}$ total column amounts from SCIAMACHY Envisat-1 nadir radiances, J. Geophys. Res., 105(D12), 15231-15245, 2000.

Burrows, J. P., Weber, M., Buchwitz, M., Rozanov, V., LadstätterWeißenmayer, A., Richter, A., Debeek, R., Hoogen, R., Bramstedt, K., Eichmann, K.-U., Eisinger, M., and Perner, D.: The Global Ozone Monitoring Experiment (GOME): Mission Concept and First Scientific Results, J. Atmos. Sci., 56, 151-171, 1999.

Butz, A., Bösch, H., Camy-Peyret, C., Chipperfield, M., Dorf, M., Dufour, G., Grunow, K., Jeseck, P., Kühl, S., Payan, S., Pepin, I., Pukite, J., Rozanov, A., von Savigny, C., Sioris, C., Wagner, T., Weidner, F., and Pfeilsticker, K.: Inter-comparison of stratospheric $\mathrm{O}_{3}$ and $\mathrm{NO}_{2}$ abundances retrieved from balloon borne direct sun observations and Envisat/SCIAMACHY limb measurements, Atmos. Chem. Phys., 6, 1293-1314, doi:10.5194/acp-61293-2006, 2006.

Coldewey-Egbers, M., Weber, M., Buchwitz, M., and Burrows, J. P.: Application of a modified DOAS method for total ozone retrieval from GOME data at high polar latitudes, Adv. Space Res., 34, 749-753, doi:10.1016/j.asr.2003.05.051, 2004.

Coldewey-Egbers, M., Weber, M., Lamsal, L. N., de Beek, R., Buchwitz, M., and Burrows, J. P.: Total ozone retrieval from GOME UV spectral data using the weighting function DOAS approach, Atmos. Chem. Phys., 5, 1015-1025, doi:10.5194/acp5-1015-2005, 2005.

Deutschmann, T.: Atmospheric radiative transfer modelling using Monte Carlo methods, Diploma Thesis, Universität Heidelberg, 2009.

Diebel, D., de Beek, R., Burrows, J. P., Kerridge, B., Munro, R., Platt, U., Marquard, L., and Muirhead, K.: Trace gas study: Detailed analysis of the retrieval algorithms selected for the level 1-2 processing of GOME data, Tech. Rep., Eur. Space Agency (ESA), Sect. 5, 5-150, 1995.

Dorf, M., Bösch, H., Butz, A., Camy-Peyret, C., Chipperfield, M. P., Engel, A., Goutail, F., Grunow, K., Hendrick, F., Hrechanyy, S., Naujokat, B., Pommereau, J.-P., Van Roozendael, M., Sioris, C., Stroh, F., Weidner, F., and Pfeilsticker, K.: Balloonborne stratospheric $\mathrm{BrO}$ measurements: comparison with Envisat/SCIAMACHY BrO limb profiles, Atmos. Chem. Phys., 6, 2483-2501, doi:10.5194/acp-6-2483-2006, 2006.
Dorf, M., Butz, A., Camy-Peyret, C., Chipperfield, M. P., Kritten, L., and Pfeilsticker, K.: Bromine in the tropical troposphere and stratosphere as derived from balloon-borne $\mathrm{BrO}$ observations, Atmos. Chem. Phys., 8, 7265-7271, doi:10.5194/acp-8-72652008, 2008.

Fleischmann, O. C., Hartmann, M., Burrows, J. P., and Orphal, J.: New ultraviolet absorption cross-sections of $\mathrm{BrO}$ at atmospheric temperatures measured by time-windowing Fourier transform spectroscopy, J. Photoch. Photobio. A, 168, 117-132, 2004.

Frankenberg, C., Platt, U., and Wagner, T.: Iterative maximum a posteriori (IMAP)-DOAS for retrieval of strongly absorbing trace gases: Model studies for $\mathrm{CH}_{4}$ and $\mathrm{CO}_{2}$ retrieval from near infrared spectra of SCIAMACHY onboard ENVISAT, Atmos. Chem. Phys., 5, 9-22, doi:10.5194/acp-5-9-2005, 2005.

Kühl, S.: Quantifying Stratospheric chlorine chemistry by the satellite spectrometers GOME and SCIAMACHY, available at: http://www.ub.uni-heidelberg.de/archiv/5664/, last access: May 2010, PhD Thesis, Universität Heidelberg, Heidelberg, Germany, 177 pp., 2005.

Kühl, S., Puķīe, J., Deutschmann, T., Platt, U., and Wagner, T.: SCIAMACHY Limb Measurements of $\mathrm{NO}_{2}, \mathrm{BrO}$ and $\mathrm{OClO}$, Retrieval of vertical profiles: Algorithm, first results, sensitivity and comparison studies, Adv. Space Res., 42, 1747-1764, 2008.

Marquard, L. C., Wagner, T., and Platt, U.: Improved Air Mass Factor Concepts for Scattered Radiation Differential Optical Absorption Spectroscopy of Atmospheric Species, J. Geophys. Res., 105, 1315-1327, 2000.

Mount, G. H., Sanders, R. W., Schmeltekopf, A. L., and Solomon, S.: Visible spectroscopy at McMurdo Station, Antarctica, 1. Overview and daily variations of $\mathrm{NO}_{2}$ and $\mathrm{O}_{3}$, austral spring, 1986, J. Geophys. Res., 92, 8320-8328, 1987.

Perliski, L. M. and Solomon, S.: On the evaluation of air mass factors for atmospheric near ultra-violet and visible absorption spectroscopy, J. Geophys. Res., 98, 10363-10374, 1993.

Perner, D., Ehhalt, D. H., Pätz, H. W., Platt, U., Röth, E. P., and Volz, A.: OH-radicals in the lower troposphere, Geophys. Res. Lett., 3, 466-468, 1976.

Platt, U., Marquard, L., Wagner, T., and Perner, D.: Corrections for zenith scattered light DOAS, Geophys. Res. Lett., 24, 17591762, 1997.

Platt, U. and Perner, D.: Direct measurements of atmospheric $\mathrm{HCHO}, \mathrm{HONO}, \mathrm{O}_{3}, \mathrm{NO}_{2}$, and $\mathrm{SO}_{2}$ by differential optical absorption in the near UV, J. Geophys. Res., 85, 7453-7458, 1980.

Platt, U.: Differential Optical Absorption Spectroscopy (DOAS), in: Air Monitoring by Spectroscopic Techniques, edited by: Sigrist, M. W., Chemical Analysis Series, John Wiley, New York, 127, 1994.

Platt, U. and Stutz, J.: Differential Optical Absorption Spectroscopy, Principles and Applications, Series: Physics of Earth and Space Environments, Springer, Heidelberg, 597 pp., doi:10.1007/978-3-540-75776-4, 2008.

Puķīte, J., Kühl, S., Deutschmann, T., Wilms-Grabe, W., Friedeburg, C., Platt, U., and Wagner, T.: Retrieval of stratospheric trace gases from SCIAMACHY limb measurements, Proceedings of the First Atmospheric Science Conference, 812 May, ESA/ESRIN, Frascati, Italy, ESA SP-628, available at: http://earth.esa.int/workshops/atmos2006/participants/1148/ paper_proc_Frasc_2.pdf, last access: 11 May 2010, 2006. 
Richter, A.: Absorptionsspektroskopische Messungen stratosphärischer Spurengase über Bremen, $53^{\circ} \mathrm{N}, \mathrm{Ph} . \mathrm{D}$. thesis, Inst. für Umweltphysik, University of Bremen, Bremen, Germany, 1997.

Rodgers, C. D.: Inverse methods for atmospheric sounding, Theory and practice, World Scientific Publishing Co. Ltd., Singapore, 2000.

Rozanov, A., Bovensmann, H., Bracher, A., Hrechanyy, S., Rozanov, V., Sinnhuber, M., Stroh, F., and Burrows, J. P.: $\mathrm{NO}_{2}$ and $\mathrm{BrO}$ vertical profile retrieval from SCIAMACHY limb measurements: Sensitivity studies, Adv. Space Res., 36(5), 846-854, doi:10.1016/j.asr.2005.03.013, 2005.

Rozanov, A., Kühl, S., Doicu, A., et al.: BrO vertical distributions from SCIAMACHY limb measurements: Comparison of algorithms and retrieval results, Atmos. Meas. Tech., in preparation, 2010.

Sheode, N., Sinnhuber, B.-M., Rozanov, A., and Burrows, J. P.: Towards a climatology of stratospheric bromine monoxide from SCIAMACHY limb observations, Atmos. Chem. Phys. Discuss., 6, 6431-6466, doi:10.5194/acpd-6-6431-2006, 2006.
Solomon, S., Schmeltekopf, A. L., and Sanders, R. W.: On the interpretation of zenith sky absorption measurements, J. Geophys. Res., 92, 8311-8319, 1987.

Stutz, J. and Platt, U.: Numerical analysis and error estimation of differential optical absorption spectroscopy measurements with least squares methods, Appl. Optics, 35, 6041-6053, 1996.

Wahner, A., Ravishankara, A., Sander, S., and Friedl, R.: Absorption cross section of BrO between 312 and $385 \mathrm{~nm}$ at 298 and 223 K, Chem. Phys. Lett., 152, 507-512, 1988.

Wahner, A., Callies, J., Dorn, H.-P., Platt, U., and Schiller, C.: Near UV atmospheric absorption measurements of column abundances during airborne Arctic stratospheric expedition, JanuaryFebruary 1989: 1. Technique and $\mathrm{NO}_{2}$ observations, Geophys. Res. Lett., 17, 497-500, 1990.

Wagner, T., Beirle, S., Deutschmann, T., Eigemeier, E., Frankenberg, C., Grzegorski, M., Liu, C., Marbach, T., Platt, U., and Penning de Vries, M.: Monitoring of atmospheric trace gases, clouds, aerosols and surface properties from UV/vis/NIR satellite instruments, J. Opt. A-Pure Appl. Op., 10, 104019, doi:10.1088/1464-4258/10/10/1040192008, 2008. 